Exchange rate returns and external adjustment:

evidence from Switzerland

Christian Grisse and Thomas Nitschka

SNB Working Papers

$12 / 2014$ 


\section{Legal Issues}

\section{DISCLAIMER}

The views expressed in this paper are those of the author(s) and do not necessarily represent those of the Swiss National Bank. Working Papers describe research in progress. Their aim is to elicit comments and to further debate.

\section{COPYRIGHTC}

The Swiss National Bank (SNB) respects all third-party rights, in particular rights relating to works protected by copyright (information or data, wordings and depictions, to the extent that these are of an individual character).

SNB publications containing a reference to a copyright (C) Swiss National Bank/SNB, Zurich/year, or similar) may, under copyright law, only be used (reproduced, used via the internet, etc.) for non-commercial purposes and provided that the source is mentioned. Their use for commercial purposes is only permitted with the prior express consent of the SNB.

General information and data published without reference to a copyright may be used without mentioning the source. To the extent that the information and data clearly derive from outside sources, the users of such information and data are obliged to respect any existing copyrights and to obtain the right of use from the relevant outside source themselves.

\section{LIMITATION OF LIABILITY}

The SNB accepts no responsibility for any information it provides. Under no circumstances will it accept any liability for losses or damage which may result from the use of such information. This limitation of liability applies, in particular, to the topicality, accuracy, validity and availability of the information.

ISSN 1660-7716 (printed version)

ISSN 1660-7724 (online version)

(C) 2014 by Swiss National Bank, Börsenstrasse 15,

P.O. Box, $\mathrm{CH}-8022$ Zurich 


\title{
Exchange rate returns and external adjustment: evidence from Switzerland
}

\author{
Christian Grisse and Thomas Nitschka* \\ Swiss National Bank
}

March 2014

\begin{abstract}
This paper studies the ability of external imbalances to indicate subsequent exchange rate returns. We propose a simple twist of the Gourinchas and Rey (2007) approximation to the intertemporal budget constraint which is valid for countries that are net creditors (or net debtors) consistently throughout the sample. Our approach offers two advantages. First, it does not require the specification of trend shares for external assets, external liabilities, exports and imports. This avoids a potential source of measurement error and can make the approximation more accurate. Second, it can be applied to countries which have historically been simultaneously net exporters and net creditors (or equivalently net importers and net debtors) on average, with the usual assumption that the no-Ponzi condition is satisfied asymptotically. This is relevant for a number of countries, e.g. Switzerland, where the original Gourinchas and Rey (2007) approximation cannot be used. We find that measures of deviations from trends in Swiss net foreign assets and net exports provide signals for future Swiss franc nominal effective exchange rate movements, both in and out of sample.
\end{abstract}

JEL classification: F31, F32, F37, G15

Keywords: external imbalances, exchange rates, Swiss franc

${ }^{*}$ Monetary Policy Analysis, Swiss National Bank, Börsenstrasse 15, P.O. Box, 8022 Zurich, Switzerland. Email: christian.grisse@snb.ch, thomas.nitschka@snb.ch. We thank Katrin Assenmacher, Pinar Yeşin, an anonymous referee of the SNB working paper series, and participants at the SNB brown bag seminar, the 2013 annual meeting of the Swiss Society of Economics and Statistics (Neuchâtel), the 4th conference on recent developments in macroeconomics (ZEW Mannheim), and the 7th International Workshop "Methods in International Finance Network" (Namur) for helpful comments and suggestions. The views expressed are those of the authors and do not necessarily reflect the position of the Swiss National Bank. 


\section{Introduction}

This paper studies the relationship between deviations from trends in net foreign assets and net exports and subsequent exchange rate returns. The recent literature has emphasized that external adjustment can occur through both trade flows and valuation effects. ${ }^{1}$ For example, net creditor countries can satisfy their intertemporal budget constraint through some combination of future trade deficits and negative returns on the external portfolio. Because exchange rate movements are one component of portfolio returns, and because exchange rates affect trade flows, net exports and net foreign assets could provide a signal for future exchange rate movements. For the link between external adjustment and valuation effects it is important to account for valuation effects, particularly for surplus countries where a large fraction of external assets is denominated in foreign currency. For such countries, even small exchange rate movements can have large effects on external positions. In an important paper, Gourinchas and Rey (2007; henceforth GR) use a linear approximation of the intertemporal budget constraint to study the US external adjustment. They derive a measure of cyclical external imbalances a linear combination of deviations from trends in assets, liabilities, exports and imports and show that this measure indicates future nominal effective US dollar exchange rate returns at time horizons between one quarter and 4 years ahead.

Building on GRs seminal paper we propose a simple twist to their approximation which is valid for countries that have consistently been net creditors (or net debtors) throughout the sample. Our approximation offers two advantages over the original GR approach. First, it does not require the specification of trend shares for external assets and liabilities as well as exports and imports, which can be a source of measurement error. Second, the method can be applied to countries where net foreign assets and net exports are both positive on average over the sample. In the GR approximation in-sample trends are used to specify the constant trend shares. For countries that are simultaneously net creditors and net exporters on average in the sample (or conversely, net debtors and net importers), extrapolating in-sample trends in this way leads to the conclusion that the intertemporal budget constraint is not satisfied. Therefore, the GR approximation cannot be applied to countries such as Germany, Japan and Switzerland that have been net exporters and net creditors for most of the post-Bretton Woods period. In contrast, our approach does not require the specification of trend shares and can therefore be applied to net creditor, net exporter countries with the usual assumption that the no-Ponzi condition is satisfied asymptotically.

The approximation proposed in this paper can be usefully applied to a number of countries. To illustrate this Figure 1 reports net exports and net foreign assets for selected countries that have been net creditors (or net debtors) for an extended period, as required for our approach. Germany and Japan have been net creditors consistently since 1980. Conversely, Australia, Italy and Spain have been net debtors to the rest of the world over most of the post-Bretton Woods period. The Figure also shows that countries that have been net exporters (net importers)

\footnotetext{
${ }^{1}$ See for example Lane and Milesi-Ferretti (2001, 2007), Lane and Shambaugh (2010), Gourinchas and Rey (2007), Gourinchas, Rey and Truempler (2012) and Evans (2012).
} 
on average have tended to be net creditors (net debtors) on average. Therefore, depending on the sample period over which the trends in external assets, external liabilities, exports and imports are computed, one is likely to find trend shares that suggest that the intertemporal budget constraint is not satisfied. Table 1 shows that this is indeed the case: for most of these countries the trend shares for exports and external assets - computed as in GR - have the same sign, implying a discount factor greater than one. This is the case even for the US over the 1970-2012 sample. ${ }^{2}$ These findings imply that the trends need to adjust out-of-sample in such a way that the intertemporal budget constraint is satisfied in the long run. Therefore the in-sample averages of the trend shares - as used in GR - in this case do not correctly reflect the long-term average trend shares.

In our empirical application we focus on Switzerland, where our approximation seems particularly relevant. As seen in Figure 1, Switzerland has been a net creditor country since 1970, and was a net exporter for most of the post-Bretton Woods period. Thus, the GR approximation is clearly not valid for Swiss data over the sample period starting in 1970. Although we find that our suggested measure of the Swiss external position is highly correlated with the original measure proposed by GR, the in-sample approximation error for the accumulation identity of the Swiss external position is smaller and less volatile than for the GR approximation. We find that both measures indicate future Swiss franc nominal effective exchange rate movements, with the proposed new approximation explaining a larger share of the variation in Swiss franc returns. Our results provide evidence supporting the original GR finding that appropriately defined measures of trend deviations in net foreign assets and net exports provide useful information about subsequent exchange rate movements, as expected based on the intertemporal budget constraint. However, this evidence should be interpreted with care since Swiss current account data are strongly affected by structural factors and statistical biases (Jordan, 2013).

We document the robustness of our preferred empirical approximation to variations in key parameters. Moreover, we also explore whether the empirical relationships found in this paper are stable over time. To do this we use the quasi-local-level test introduced by Elliott and Mller (2006) to test for gradual time variation in regression coefficients. There is no reason why the coefficients should be stable. In particular, as the currency denomination of external assets and liabilities changes the sensitivity of returns on the external portfolio to exchange rate movements will change also. Additionally, the elasticity of trade flows to exchange rates could change over time as well. Perhaps surprisingly, we cannot reject the null hypothesis that the link between trend deviations in Swiss net exports and net foreign assets and subsequent movements in the Swiss franc effective exchange rate is stable at conventional levels of significance.

The next section begins by reviewing the methodology introduced by GR. The objective is to highlight which assumptions can be problematic in the empirical application, and discusses how these assumptions can be relaxed. Then an alternative approximation is proposed. Section 3 applies our methodology to Switzerland, and explores the link between this approximation of

\footnotetext{
${ }^{2}$ However, this is not the case over the longer 1952-2004 sample that was considered in GR. Of course to obtain accurate estimates of the long-term trends it is important to have a sufficiently long sample period, but data on external positions is typically only available from 1970.
} 
the Swiss intertemportal budget constraint and Swiss franc movements. Section 4 discusses the robustness of our results for alternative approximations of the intertemporal budget constraint, and tests whether the empirical relationships found in this paper between are stable over time. Finally, section 5 concludes.

\section{Empirical framework}

\subsection{The intertemporal budget constraint}

Countries face an asset accumulation identity of the form

$$
N F A_{t+1}=R_{t+1}\left(N F A_{t}+N X_{t}\right)
$$

where $N F A_{t}$ denotes net foreign assets, $N X_{t}$ denotes net exports and $R_{t}$ is the ex-post gross portfolio return. In (1) we follow the timing convention of GR, with net foreign assets measured at the beginning of the period. For comparability with the setup in typical macroeconomic models it is common to divide by wealth $W_{t}$

$$
n f a_{t+1}=\frac{R_{t+1}}{\Gamma_{t+1}}\left(n f a_{t}+n x_{t}\right)
$$

where $\Gamma_{t+1} \equiv W_{t+1} / W_{t}$ and small letters denote variables divided by wealth. Solving (2) forward and assuming that the no-Ponzi condition holds produces the intertemporal budget constraint,

$$
n f a_{t}=-\sum_{j=0}^{\infty} R_{t, t+j} n x_{t+j}
$$

where $R_{t, t+j} \equiv\left(\Gamma_{t+1} \times \Gamma_{t+2} \times \ldots \times \Gamma_{t+j}\right) /\left(R_{t+1} \times R_{t+2} \times \ldots \times R_{t+j}\right)$ with $R_{t, t} \equiv 1$. Since (3) holds ex-post and ex-ante it will also hold under rational expectations, taken conditional on information available in period $t$ :

$$
n f a_{t}=-\mathbb{E}_{t}\left(\sum_{j=0}^{\infty} R_{t, t+j} n x_{t+j}\right)
$$

The implication of (4) is that positive net foreign assets should predict either trade deficits or negative portfolio returns, or both. Moreover, because exchange rate changes are one determinant of the portfolio return, net foreign assets should also predict movements in exchange rates.

The problem with using equation (4) as a starting point for empirical work is that the relationship between net foreign assets, net exports and portfolio returns is non-linear. This is the case because $R_{t, t+j}$ is the product of individual one-period growth-adjusted portfolio returns, each of which depends on portfolio weights, returns on individual types of assets and liabilities, and exchange rate changes. The contribution of GR was to suggest a linear approximation 
of (4), following Campbell and Shiller (1988), Campbell and Mankiw (1989) and Lettau and Ludvigson (2001). The next subsection reviews the approach introduced by GR and discusses alternative ways of implementing it.

\subsection{Linear approximations to the intertemporal budget constraint}

A linear approximation to the accumulation identity. To log-linearize, GR first disaggregate net foreign assets and net exports in equation (2) to work only with variables which are positive by definition:

$$
\Gamma_{t+1}\left(\hat{A}_{t+1}-\hat{L}_{t+1}\right)=R_{t+1}\left(\hat{A}_{t}-\hat{L}_{t}+\hat{X}_{t}-\hat{M}_{t}\right)
$$

where $\hat{A}_{t}-\hat{L}_{t}=n f a_{t}, \hat{X}_{t}-\hat{M}_{t}=n x_{t}$ and $\hat{Z}_{t} \equiv Z_{t} / W_{t}$ for $Z_{t} \in\left\{A_{t}, L_{t}, X_{t}, M_{t}\right\}$. For US data GR note that the ratios of assets, liabilities, exports and imports to wealth are trending over time. They argue that these trends are for the most part unrelated to the cyclical adjustment of exchange rates, and therefore focus on the implications of trend deviations for external adjustment. Let $\bar{Z}_{t}$ denote the trend of $\hat{Z}_{t}$ for $Z_{t} \in\left\{A_{t}, L_{t}, X_{t}, M_{t}\right\}$, with $\bar{R}_{t}$ and $\bar{\Gamma}_{t}$ denoting the trends of $R_{t}$ and $\Gamma_{t}$, and define trend deviations as

$$
\begin{aligned}
\epsilon_{t}^{z} & \equiv \ln \hat{Z}_{t}-\ln \bar{Z}_{t} \\
\epsilon_{t+1}^{\Delta w} & \equiv \ln \Gamma_{t+1}-\ln \bar{\Gamma}_{t+1} \\
\hat{r}_{t+1} & \equiv \ln R_{t+1}-\ln \bar{R}_{t+1}
\end{aligned}
$$

The following assumption allows GR to log-linearize (5) around the trends.

Assumption 1 The trend deviations $\epsilon_{t}^{z}, \hat{r}_{t}$ and $\epsilon_{t}^{\Delta w}$ are stationary and small: $\left|\epsilon_{t}^{z}\right|,\left|\hat{r}_{t}\right|$ and $\left|\epsilon_{t}^{\Delta w}\right| \ll 1$ for $z \in\{a, l, x, m\}$.

With this assumption a first-order Taylor series expansion of (5) around the point where $\epsilon_{t}^{a}=$ $\epsilon_{t}^{l}=\epsilon_{t}^{x}=\epsilon_{t}^{m}=0$ gives

$$
\begin{aligned}
& \ln \left(\bar{\Gamma}_{t+1}\right)+\epsilon_{t+1}^{\Delta w}+\ln \left(\bar{A}_{t+1}-\bar{L}_{t+1}\right)+n a_{t+1} \\
\approx & \ln \left(\bar{R}_{t+1}\right)+\hat{r}_{t+1}+\ln \left(\bar{A}_{t}-\bar{L}_{t}+\bar{X}_{t}-\bar{M}_{t}\right)+\frac{1}{\rho_{t}} n a_{t}+\left(1-\frac{1}{\rho_{t}}\right) n x_{t}
\end{aligned}
$$

where

$$
\begin{aligned}
n a_{t} & \equiv \mu_{t}^{a} \epsilon_{t}^{a}-\mu_{t}^{l} \epsilon_{t}^{l} \\
n x_{t} & \equiv \mu_{t}^{x} \epsilon_{t}^{x}-\mu_{t}^{m} \epsilon_{t}^{m} \\
\rho_{t} & \equiv 1+\frac{\bar{X}_{t}-\bar{M}_{t}}{\bar{A}_{t}-\bar{L}_{t}}
\end{aligned}
$$

and

$$
\mu_{t}^{a} \equiv \frac{\bar{A}_{t}}{\bar{A}_{t}-\bar{L}_{t}}, \mu_{t}^{x} \equiv \frac{\bar{X}_{t}}{\bar{X}_{t}-\bar{M}_{t}}, \mu_{t}^{l} \equiv \mu_{t}^{a}-1, \mu_{t}^{m} \equiv \mu_{t}^{x}-1
$$


With the next assumption the trend terms in (6) drop out.

Assumption 2 The trends satisfy the accumulation identity:

$$
\bar{\Gamma}_{t+1}\left(\bar{A}_{t+1}-\bar{L}_{t+1}\right)=\bar{R}_{t+1}\left(\bar{A}_{t}-\bar{L}_{t}+\bar{X}_{t}-\bar{M}_{t}\right)
$$

After using assumption 2 and rearranging (6) simplifies to

$$
\left(n a_{t+1}-n x_{t+1}\right) \approx \hat{r}_{t+1}+\frac{1}{\rho_{t}}\left(n a_{t}-n x_{t}\right)-\left(n x_{t+1}-n x_{t}+\epsilon_{t+1}^{\Delta w}\right)
$$

Now we would like to solve (11) forward to obtain a linear approximation of the intertemporal budget constraint (3). This requires that $\rho_{t}<1$, at least in the limit as $t \rightarrow \infty$. From (9) this is the case if, as $t \rightarrow \infty$, the trend shares $\mu_{t}^{a}$ and $\mu_{t}^{x}$ have opposite signs: in the long run net creditor countries run trade deficits, while conversely net debtor countries run trade surpluses.

Time varying trend shares. Define

$$
\begin{aligned}
n x a_{t} & \equiv n a_{t}-n x_{t} \\
\Delta n x_{t+1} & \equiv n x_{t+1}-n x_{t}+\epsilon_{t+1}^{\Delta w}
\end{aligned}
$$

Then (11) becomes

$$
n x a_{t+1} \approx \hat{r}_{t+1}+\frac{1}{\rho_{t}} n x a_{t}-\Delta n x_{t+1}
$$

Assumption 3 nxa $a_{t}$ satisfies the no-Ponzi condition $\lim _{j \rightarrow \infty} \rho_{t+j} n x a_{t+j+1}=0$ with probability one.

With this assumption we can solve (14) forward to obtain

$$
n x a_{t} \approx \sum_{j=1}^{\infty} \hat{\rho}_{t+j-1}\left(\Delta n x_{t+j}-\hat{r}_{t+j}\right)
$$

where $\hat{\rho}_{t+j} \equiv \rho_{t} \times \rho_{t+1} \times \ldots \times \rho_{t+j}$. In equation (15) $n x a_{t}$ and $\Delta n x_{t}$ are computed using timevarying trend shares $\mu_{t}^{a}, \mu_{t}^{l}, \mu_{t}^{x}, \mu_{t}^{m}$. In practice these weights may be imprecisely measured. In particular, the trend shares will exhibit extreme non-linear movements around points in the sample where $\bar{A}_{t} \approx \bar{L}_{t}$ and $\bar{X}_{t} \approx \bar{M}_{t}$. GR therefore work with constant trend shares.

Constant trend shares. GR simplify by assuming that $\hat{A}_{t}, \hat{L}_{t}, \hat{X}_{t}, \hat{M}_{t}$ share a common trend, which allows them to work with constant trend shares.

Assumption 4 The trend components $\bar{Z}_{t}$ for $Z_{t} \in\left\{A_{t}, L_{t}, X_{t}, M_{t}\right\}$ admit a common, possibly time-varying growth rate: $\bar{Z}_{t}=\bar{Z} \mu_{t}$. 
With this assumption the trend shares are constant:

$$
\begin{aligned}
\mu_{t}^{a} & =\frac{\bar{A}}{\bar{A}-\bar{L}} \equiv \mu^{a} \\
\mu_{t}^{x} & =\frac{\bar{X}}{\bar{X}-\bar{M}} \equiv \mu^{x} \\
\rho_{t} & =1+\frac{\bar{X}-\bar{M}}{\bar{A}-\bar{L}} \equiv \rho
\end{aligned}
$$

To solve the accumulation identity forward we require that $\rho<1$. From (18) and (2) we see that this is the case if

$$
\rho=\frac{\bar{\Gamma}_{t+1}}{\bar{R}_{t+1}} \frac{\mu_{t+1}}{\mu_{t}}<1
$$

This is ensured (asymptotically) by the following assumption.

Assumption 5 The deterministic economy eventually settles into a balanced growth path:

a. Asymptotically, $\lim _{t \rightarrow \infty} \mu_{t}=1$.

b. The trend return $\bar{R}_{t+1}$ and growth rate $\bar{\Gamma}_{t+1}$ converge to $R$ and $\Gamma$ such that $R>\Gamma$.

If $\rho<1$ then $\mu^{a}$ and $\mu^{x}$ have opposite signs and (11) simplifies to

$$
n x a_{t+1} \approx \frac{1}{\rho} n x a_{t}+r_{t+1}+\Delta n x_{t+1}
$$

where

$$
\begin{aligned}
n x a_{t} & \equiv\left|\mu^{a}\right| \epsilon_{t}^{a}-\left|\mu^{l}\right| \epsilon_{t}^{l}+\left|\mu^{x}\right| \epsilon_{t}^{x}-\left|\mu^{m}\right| \epsilon_{t}^{m} \\
\Delta n x_{t+1} & \equiv\left|\mu^{x}\right| \Delta \epsilon_{t+1}^{x}-\left|\mu^{m}\right| \Delta \epsilon_{t+1}^{m}-\epsilon_{t+1}^{\Delta w} \\
r_{t+1} & \equiv \frac{\mu_{t}^{a}}{\left|\mu_{t}^{a}\right|} \hat{r}_{t+1}
\end{aligned}
$$

Under assumption 3 we can then solve forward to obtain an approximation of the intertemporal budget constraint,

$$
n x a_{t} \approx-\sum_{j=1}^{\infty} \rho^{j}\left(r_{t+j}+\Delta n x_{t+j}\right)
$$

The use of constant trend shares mitigates the problem of measurement error, which could magnify the volatility of the trend shares. ${ }^{3}$ In their empirical application GR therefore calculate $\bar{Z}$ in (16)-(18) as the in-sample average of $\bar{Z}_{t}$, which is valid if assumption 4 holds. In particular, this approach makes sense for US data where assets, liabilities, exports and imports do exhibit

\footnotetext{
${ }^{3}$ The variable $n x a_{t}$ in equation (20) can equivalently be expressed as

$$
n x a_{t}=\left|\mu^{m}\right| \epsilon_{t}^{x m}+\left|\mu^{l}\right| \epsilon_{t}^{a l}+\epsilon_{t}^{x a}
$$

where $\epsilon_{t}^{x m}, \epsilon_{t}^{a l}$ and $\epsilon_{t}^{x a}$ are the trend deviations of the stationary ratios $\hat{X}_{t} / \hat{M}_{t}, \hat{A}_{t} / \hat{L}_{t}$ and $\hat{X}_{t} / \hat{A}_{t}$. Gourinchas and Rey (2005) and Cardarelli and Konstantinou (2007) construct $n x a_{t}$ from this alternative formulation, using cointegration methods to estimate $\epsilon_{t}^{x m}, \epsilon_{t}^{a l}$ and $\epsilon_{t}^{x a}$. See also Corsetti and Konstantinou (2012) for a related approach.
} 
similar trends. For many countries, however, the assumption of a common in-sample trend in $\hat{A}_{t}, \hat{L}_{t}, \hat{X}_{t}, \hat{M}_{t}$ may not be a good description of the data. Often a more reasonable assumption may be that assets and liabilities exhibit a common trend, and that similarly exports and imports share a common trend. In this case one can follow Evans (2012) and rewrite the accumulation identity (5) as

$$
\Gamma_{t+1}\left(\hat{A}_{t+1}-\hat{L}_{t+1}\right)=R_{t+1}\left(\hat{A}_{t}-\hat{L}_{t}+\hat{X}_{t}^{*}-\hat{M}_{t}^{*}\right)
$$

where $\hat{X}_{t}^{*} \equiv \hat{X}_{t}+\tau_{t}$ and $\hat{M}_{t}^{*} \equiv \hat{M}_{t}+\tau_{t}$, and $\tau_{t}$ is chosen such that $\hat{X}_{t}^{*}, \hat{M}_{t}^{*}$ and $\hat{A}_{t}, \hat{L}_{t}$ exhibit a common trend. While $\tau_{t}$ cancels out in (24), this is not the case in its first-order approximation. On the one hand the introduction of $\tau_{t}$ adds some additional noise to the approximation; on the other hand, it may make the assumption of a common trend more reasonable.

A more serious problem is that the constant trend shares $\mu^{a}$ and $\mu^{x}$ identified in this way may have the same signs, so that $\rho>1$. For example, countries such as Switzerland and Germany have been net exporters over the last decades, and as a result have built up large positive net foreign assets. For such countries, if in-sample trends are extrapolated the data would imply that the intertemporal budget constraint is not satisfied. ${ }^{4}$

\subsection{An alternative approach for net creditor countries}

This section introduces a linear approximation to the accumulation identity (2) which is valid for net creditor countries. The approximation is similar to that proposed in Whelan (2008) for consumers' budget constraints, but as in GR we log-linearize around the trends of net foreign assets and net exports.

Assumption 6 Net foreign assets $n f a_{t}$ are positive throughout the sample.

Begin by defining net imports as $n i_{t} \equiv-n x_{t}$ and write $(2)$ as

$$
\Gamma_{t+1} n f a_{t+1}=R_{t+1}\left(n f a_{t}-n i_{t}\right)
$$

Now the trick is to rewrite $(25)$ as

$$
\Gamma_{t+1} n f a_{t+1}=R_{t+1}\left(n f a_{t}^{*}-n i_{t}^{*}\right)
$$

where

$$
\begin{aligned}
n f a_{t}^{*} & \equiv n f a_{t}+\tau_{t} \\
n i_{t}^{*} & \equiv n i_{t}+\tau_{t}
\end{aligned}
$$

\footnotetext{
${ }^{4}$ The trend deviations $\epsilon_{t}^{a}, \epsilon_{t}^{l}, \epsilon_{t}^{x}$ and $\epsilon_{t}^{m}$ can also be used directly as explanatory variables in predictive regressions. The advantage of this approach is that potential measurement error in the estimation of the trend shares is avoided. The disadvantage is that this approach does not use all available information, which makes it more difficult to identify a statistically significant relationship between the trend deviations and the variables on the right-hand side of (15).
} 
and $\tau_{t}>0$ is an adjustment factor which is sufficiently large to ensure that $n i_{t}^{*}>0$ for all $t$. Clearly the accumulation identity is unaffected by the introduction of $\tau_{t}{ }^{5}$

Following GR we allow for the possibility that the variables exhibit trends. Taking logs equation (26) then becomes

$$
\ln \left(\bar{\Gamma}_{t+1}\right)+\epsilon_{t+1}^{\Delta w}+\ln \left(\overline{n f a}_{t+1}\right)+\epsilon_{t+1}^{n f a}=\ln \left(\bar{R}_{t+1}\right)+\hat{r}_{t+1}+\ln \left(n f a_{t}^{*}-n i_{t}^{*}\right)
$$

Using assumption 1 we can take a first-order Taylor series expansion of the last term on the right-hand side around the point where $\varepsilon_{t}^{n f a *}=\varepsilon_{t}^{n i *}=0$. Substituting the result into (27) we get

$\ln \left(\bar{\Gamma}_{t+1}\right)+\epsilon_{t+1}^{\Delta w}+\ln \left(\overline{n f a}_{t+1}\right)+\epsilon_{t+1}^{n f a} \approx \ln \left(\bar{R}_{t+1}\right)+\hat{r}_{t+1}+\ln \left(\overline{n f a}_{t}^{*}-\overline{n i}_{t}^{*}\right)+\frac{1}{\rho_{t}} \epsilon_{t}^{n f a *}+\left(1-\frac{1}{\rho_{t}}\right) \epsilon_{t}^{n i *}$

where

$$
\rho_{t} \equiv 1-\frac{\overline{n i}_{t}^{*}}{\overline{n f a}_{t}^{*}}
$$

Using assumption 2 applied to equation (26), the trends drop out and (28) simplifies to

$$
\epsilon_{t+1}^{\Delta w}+\epsilon_{t+1}^{n f a} \approx \hat{r}_{t+1}+\frac{1}{\rho_{t}}\left(\epsilon_{t}^{n f a *}-\epsilon_{t}^{n i *}\right)+\epsilon_{t}^{n i *}
$$

Subtracting $\epsilon_{t+1}^{n i *}$ and adding $\epsilon_{t+1}^{n f a *}$ on both sides and rearranging gives

$$
n x a_{t+1}^{*} \approx \hat{r}_{t+1}+\frac{1}{\rho_{t}} n x a_{t}^{*}+\Delta n x_{t+1}^{*}+\varepsilon_{t+1}^{*}
$$

where

$$
\begin{aligned}
n x a_{t}^{*} & \equiv \epsilon_{t}^{n f a *}-\epsilon_{t}^{n i *} \\
\Delta n x_{t+1}^{*} & \equiv-\left(\epsilon_{t+1}^{n i *}-\epsilon_{t}^{n i *}+\epsilon_{t+1}^{\Delta w}\right) \\
\varepsilon_{t}^{*} & \equiv \epsilon_{t}^{n f a *}-\epsilon_{t}^{n f a}
\end{aligned}
$$

Here we have used stars to emphasize the difference to the variables introduced by GR in (20) and (21). Note that $n x a_{t}$ and $n x a_{t}^{*}$ are both increasing in shocks which increase exports and assets relative to their trends, and decreasing in shocks that increase imports and liabilities above their trends. Since $\rho_{t}<1$ we can solve forward, imposing assumption 3, to obtain an approximation of the intertemporal budget constraint (3),

$$
n x a_{t}^{*} \approx-\sum_{j=1}^{\infty} \hat{\rho}_{t+j-1}\left(\hat{r}_{t+j}+\Delta n x_{t+j}^{*}+\varepsilon_{t+j}^{*}\right)
$$

where $\hat{\rho}_{t+j} \equiv \rho_{t} \times \rho_{t+1} \times \ldots \times \rho_{t+j}$.

\footnotetext{
${ }^{5}$ The case where $n f a_{t}<0$ throughout the sample can be equivalently handled by letting $n f l_{t} \equiv-n f a_{t}$, $n f l_{t}^{*} \equiv n f l_{t}+\tau_{t}$ and $n x_{t}^{*} \equiv n x_{t}+\tau_{t}$. Then (26) can be written as $\Gamma_{t+1} n f l_{t+1}=R_{t+1}\left(n f l_{t}^{*}-n x_{t}^{*}\right)$.
} 
There are alternative ways to implement approximation (34) in practice. First, one could set $\tau_{t}$ equal to a constant that is sufficiently large to ensure that $n i_{t}^{*}$ is always positive. Second, one could choose $\tau_{t}=\theta n f a_{t}$, where $\theta>0$ would again be a positive and sufficiently large constant. ${ }^{6}$ This second approach is similar to the approximation suggested by Whelan (2008) for the domestic budget constraint. In this paper we mainly focus on the first approach, for two reasons. First, with $\tau_{t}$ equal to a constant the implications of the choice of $\tau_{t}$ for the out-ofsample validity of the approximation are straightforward. In contrast, the required value of $\theta$ to ensure that $n i_{t}^{*}>0$ for a reasonably long out-of-sample period depends on the projected path for net foreign assets. Second, in the application to Swiss data reported in section 3 we found that $n x a^{*}$ with a constant adjustment factor exhibits a stronger and more robust relationship with Swiss franc returns. We relegate results for $n f a^{*}$ adjusted with $\tau_{t}=\theta n f a_{t}$ to the robustness checks in section 4.

To what extent does (34) represent a good approximation of the non-linear intertemporal budget constraint? In-sample the approximation accuracy of (30) can be checked directly. However, the derivation only makes sense if assumption 6 remains satisfied out-of-sample (or in practice, for a sufficiently long out-of-sample period). This is likely to be the case for countries which have sufficiently large net foreign assets at the end of the sample period. Also, if $n x a_{t}^{*}$ is found to forecast $\Delta n x_{t+1+j}^{*}$ and/or $\hat{r}_{t+1+j}$ this can be interpreted as indirect evidence that approximation (34) is valid. Finally, note that (34) can be applied to countries which are both net creditors and net exporters throughout the sample (or conversely, simultaneously net debtors and net importers).

\section{An application to Swiss data}

\subsection{Measuring Swiss external imbalances}

In this section we compare alternative measures of Swiss external imbalances for the postBretton Woods period. ${ }^{7}$ In Figure 1 it was seen that Switzerland has been running persistent trade surpluses for most of the sample period, and has built up a large stock of net foreign assets as a result. ${ }^{8}$ From the perspective of the present value relation (3) Switzerland will eventually begin to run trade deficits, or will have to incur losses on its foreign portfolio to satisfy its intertemporal budget constraint. The ratios of Swiss external assets, external liabilities, exports and imports, as well as net foreign assets and net exports to GDP have been trending upwards

\footnotetext{
${ }^{6}$ In the empirical implementation of (20) and (31) we follow GR and detrend the log of the variables. For example, we calculate $\overline{n f a}_{t}$ not as the trend of $n f a_{t}$ but as the exponential of the trend of the $\log$ of $n f a_{t}$. With this specification it is not difficult to see that setting $\tau_{t}=\theta n f a_{t}$ implies $\epsilon_{t}^{n f a *}=\epsilon_{t}^{n f a}$ and hence $\varepsilon_{t}^{*}=0$ for all $t$.

${ }^{7}$ See the appendix for details on data sources. In contrast to GR we use nominal GDP, rather than household wealth, as a deflator in equation (2). For Switzerland GDP data is available for a longer period, and is of better quality than data on household net worth. However, our results are robust to using household net worth as a measure of wealth instead, and to approximating the accumulation identity (1) directly in levels without dividing by wealth.

${ }^{8}$ The increase in Switzerland's net foreign assets has been smaller than what is implied by the size of current account surpluses. This is because of valuation changes, as discussed in Stoffels and Tille (2007). Note also that the economically relevant size of the current account surplus is smaller than its measured size. See Jordan (2013) and IMF (2012, annex I) on this point.
} 
over time. GR argue that such long-term trends reflect structural changes in the economy, such as declining transport and transaction costs, which are unrelated to (cyclical) external adjustment. We therefore follow GR and focus on the implications of deviations in the trends of external imbalances for exchange rate movements. Of course, to the extent that the observed trends themselves are inconsistent with the intertemporal budget constraint they would have additional implications for exchange rates. However it is difficult to quantify these additional effects because they would not reflect empirical patterns already observed in the sample.

In the following we denote by $n x a$ the GR measure of cyclical imbalances computed using constant trend shares in equation (20). ${ }^{9}$ Recall from section 2.2 that the approximation of the accumulation identity using $n x a_{t}$ in (19) is only valid if $\mu^{a}$ and $\mu^{x}$ have opposite signs. For Switzerland, however, we find $\mu^{x} \approx 10.97, \mu^{a} \approx 3.26$ and $\rho \approx 1.01$. That also implies that assumption 3 is not satisfied. This is not surprising: as Figure 1 makes clear, if we extrapolate the in-sample trends of Swiss external imbalances we conclude that the intertemporal budget constraint is not satisfied. Despite these problems we report $n x a$ for purposes of comparison with the alternative approximation suggested in section 2.3. In any case, as we show below $n x a$ has strong predictive power for Swiss franc exchange rates, at least in-sample.

Based on the approximation suggested in (31) we compute $n x a^{*}$ by setting $\tau_{t}$ equal to a constant. As discussed above, this approximation has two advantages for Swiss data relative to the GR measure. First, it is theoretically correct despite the fact that Switzerland has been simultaneously a net creditor and net exporter in-sample; and second, it does not require the specification of the trend shares $\mu_{t}^{a}$ and $\mu_{t}^{x}$. In the empirical implication we set $\tau_{t}=$ $\max \left(n x_{t}\right)+\tau$, where the maximum value of net exports in the sample is about 12 percent of (quarterly) GDP. In the baseline results reported in this section we use $\tau=0.05$ as a compromise between minimizing the approximation error (which increases with a larger $\tau$ ) and ensuring that adjusted net imports $n i_{t}^{*}$ remain positive out-of-sample. With $\tau=0.05$ the approximation remains valid out-of-sample even if net exports were to rise from below 10 percent of (quarterly) GDP at the end of the sample to 17 percent of GDP. Note that the logic of the intertemporal budget constraint implies that Switzerland should eventually start to run trade deficits. In section 4 we show that our main results are robust to alternative choices of $\tau$. As reported there, $n x a^{*}$ computed with adjustment factors as high as $\tau=0.4$-i.e., allowing net exports to rise to more than 50 percent of GDP - still result in an approximation with very strong insample predictive power for exchange rate returns. The out-of-sample forecasting performance, however, suffers as $\tau$ is increased beyond 0.1 .

Figure 2 shows time series for $n x a$ and $n x a^{*}$. The two measures move closely together. Figure 3 plots $n x a^{*}$ along with its approximation error, computed by subtracting the right-hand side of (30) from the left hand side. ${ }^{10}$ For better comparison with GR we also report the error for the $n x a^{*}$ approximation computed using a constant discount rate $\rho$, obtained by replacing

\footnotetext{
${ }^{9}$ We follow GR and detrend all variables (in logs) using an HP filter with $\lambda=2400000$, filtering out only long-term trends. Our results are unchanged if we use a linear trend instead.

${ }^{10}$ To compute the approximation error we need data on the ex-post portfolio return $R_{t}$. Rather than constructing this from data on portfolio shares and returns on individual assets and liabilities, we compute $R_{t}$ as implied by the accumulation identity (1), given data on net foreign assets and net exports.
} 
the trends of adjusted net foreign assets and net imports in (29) by their sample averages. The chart shows that the approximation error is small relative to the size of $n x a^{*}$. Figure 4 contrasts the approximation errors of $n x a$ and $n x a^{*}$. The standard deviation of $n x a$ is about 30 times larger than the standard deviation of the corresponding approximation error. For $n x a^{*}$, the standard deviation is 40 times larger than that of its approximation error. This suggests that $n x a^{*}$ is somewhat more accurate than the (for Switzerland not theoretically correct) $n x a$ approximation. ${ }^{11}$

While $n x a^{*}$ does not depend on the specification of the discount rate, its estimated approximation error does. When this error is computed using a time-varying discount rate - the green line in Figure 4 - the error is very persistent and exhibits an upward trend from the beginning of the sample until 2000, with a decline over the last years in the sample. This pattern reflects the trend in the estimated discount rate, which in turn from (29) is driven by the trends in (adjusted) net foreign assets and net imports. With net exports increasing for most of the sample, adjusted net imports are declining. Because net foreign assets are also growing over time this results in an increase in the discount rate from 0.93 in 1973 to 0.99 at the end of the sample. In contrast, the approximation error of $n x a^{*}$ appears to be stationary when a constant discount rate is used as in GR.

\subsection{Forecasting Swiss franc effective exchange rates}

The intertemporal budget constraint implies that current external imbalances should predict some combination of future net export growth and future returns on the external portfolio. Because exchange rate changes contribute to returns when some fraction of external assets or liabilities are denominated in foreign currency, and because exchange rates affect trade flows, current external imbalances should also have predictive power for exchange rate movements. Here we explore whether this is the case for alternative approximations of the intertemporal budget constraint. To illustrate the link between cyclical Swiss external imbalances and subsequent movements in the Swiss franc Figure 6 plots $n x a^{*}$ against 4-, 8- and 12- quarter ahead Swiss franc returns. The Figure illustrates that for many historical episodes, increases in Swiss cyclical external imbalances were associated with a subsequent appreciation of the Swiss franc. However, the positive correlation is not perfect, indicating that other variables - perhaps measures of risk - have also been important drivers of Swiss franc returns.

We run regressions of the form

$$
\Delta e_{t+k}=\beta_{0}+\beta_{1} X_{t}+\varepsilon_{t}
$$

where $\Delta e_{t+k} \equiv \ln \left(E_{t+k} / E_{t}\right) / k$ is the log return of the Swiss franc nominal effective (exportweighted) exchange rate between quarters $t$ and $t+k$, defined such that an increase corresponds to a Swiss franc appreciation, and $X_{t} \in\left\{n x a_{t}, n x a_{t}^{*}\right\}$ is a measure of external imbalances (normalized to have a standard deviation of one). We run regressions from 1980Q1 to 2011 Q2

\footnotetext{
${ }^{11}$ With a constant adjustment factor $\tau=\max \left(n x_{t}\right)+0.05$ the term $\varepsilon_{t}^{*}$ in $(26)$ is close to zero on average, with a standard deviation below 0.01 .
} 
to exclude both the period of the introduction of the exchange rate floor versus Deutsche Mark by the Swiss National Bank (SNB) in October 1978, as well as the most recent period after the introduction of the Swiss franc minimum rate against the euro in September 2011.12

The expected sign of $\beta_{1}$ depends on the share of assets and liabilities denominated in foreign currency. For Switzerland, SNB data shows that between 1983 and 2011 the share of external assets denominated in foreign currency rose from 60 to about 80 percent, while the share of external liabilities denominated in foreign currency was much lower, fluctuating between 30 and 50 percent (see Figure 5). Since Swiss net foreign assets were also positive throughout the sample period this implies that a Swiss franc appreciation corresponds to a negative return on the external portfolio over the period that we study. Based on the currency decomposition of the Swiss external position we would therefore expect a positive coefficient for $\beta_{1}$, i.e. abovetrend external imbalances should forecast an appreciation of the Swiss franc effective exchange rate (a negative return on the external portfolio). The expectation that we should find $\beta_{1}>0$ is reinforced by the effect of an appreciation on net exports.

The results are reported in Table 2, for forecast horizons $k$ up to 16 quarters. The numbers in parentheses are Newey-West standard errors with $k-1$ lags to account for the serial correlation of the residuals induced by forecasting overlapping returns. Both measures of Swiss external imbalances exhibit a strong relationship with subsequent Swiss franc returns, with the expected positive coefficient. In particular, the link between $n x a^{*}$ and future Swiss franc returns is statistically significant at the 1 percent level for forecast horizons between 1 and 10 quarters ahead. The strongest effects occur within the first year: a one standard deviation increase in $n x a^{*}$ is associated with a 0.6 percent per quarter appreciation of the Swiss franc effective exchange rate in the first four quarters. The strength of the effect gradually declines for longer forecast horizons. The adjusted $R^{2}$ is always higher for the regressions with $n x a^{*}$ than for $n x a$, peaking at 0.21 for the $4-5$ quarters ahead regressions.

Next we ask whether trend deviations in external imbalances also have predictive power for Swiss franc returns out-of-sample. We proceed as follows. Let $T_{0}$ and $T_{2}$ denote the initial and last observations in the sample, and choose $T_{1}$ such that $T_{0}<T_{1}<T_{2}$. First, we construct $n x a$ and $n x a^{*}$ and estimate regression (35) for the initial "in-sample" from $T_{0}$ to $T_{1}$. We then use the last in-sample observations $n x a_{T_{1}}$ and $n x a_{T_{1}}^{*}$ together with the estimated coefficients to predict the first out-of-sample non-overlapping Swiss franc return, i.e. the return between $T_{1}$ and $T_{1}+k$. Next we roll-over the in-sample by one quarter, so that the new in-sample runs from $T_{0}+1$ to $T_{1}+1$. We repeat the same steps as above, constructing $n x a$ and $n x a^{*}$, performing the in-sample regression and using the $n x a$ and $n x a^{*}$ from period $T_{1}+1$ to predict Swiss franc returns between $T_{1}+1$ and $T_{1}+1+k$. Continuing in this fashion we compute forecasts for $T_{1}+1$ to $T_{2}$. As the cutoff for the initial in-sample $\left(T_{1}\right)$ we choose 1999 Q4 to leave a sufficient number of observations to estimate the parameters accurately. ${ }^{13}$

\footnotetext{
${ }^{12}$ For information about the exchange rate floor in 1978 see for example SNB (2007), Bernanke et al. (2001; chapter 4) and Rich (2003).

${ }^{13}$ Unlike Meese and Rogoff (1983) we test ex-ante forecasting power and do not compute forecasts using realized values.
} 
Table 3 presents the results. Because the constants in the regressions reported in Table 2 are highly significant - the Swiss franc has appreciated on average over the sample period -, we compare forecasting power of external imbalances against both a driftless random walk (as is standard in the literature) and against a random walk with drift. A ratio $M S P E_{n x a} / M S P E_{r w}$ and $M S P E_{n x a} / M S P E_{r w d}$ below one indicates that regression model (35) has a smaller mean square prediction error than the random walk without/with drift in forecasting Swiss franc returns out-of-sample. Since regression (35) nests the random walk models we report the Clark and West (2006) statistic, $\triangle M S P E$-adjusted, to test whether any improvement in the mean square prediction error due to the inclusion of approximated external imbalances is statistically significant. ${ }^{14}$ For the comparison with a random walk with drift the distribution of the test statistic is non-standard (because the null model relies on the estimation of the mean exchange rate return), but close to the standard normal distribution. Therefore significance levels are reported based on the standard normal distribution. The null that trend deviations in external imbalances do not have predictive power is rejected if $\triangle M S P E$-adjusted is sufficiently large.

The forecasts from the $n x a$ and $n x a^{*}$ models both have a lower mean square prediction error than the random walk model, but this may simply reflect the trend appreciation of the Swiss franc. Improving upon forecasts from a random walk with drift is harder. For forecast horizons of 2, 4-6, and 10-12 quarters ahead the $n x a^{*}$ model has a lower MSPE than the random walk with drift. Also, the Clark and West (2006) tests shows that for the 2, 4-6 and 12 quarters ahead regressions this improvement is statistically significant at the $5 \%$ level. This suggests that when the uncertainty about the regression parameters in the unrestricted models is taken into account, Swiss external imbalances do have out-of-sample forecasting power for medium-term Swiss franc movements. The improvement upon the random walk with drift model is weaker with an earlier break date. For example, with 1995 Q4 as the initial out-of-sample period ensuring an equal number of observations in the in- and out-sample - the improvement of the $n x a^{*}$ model upon the random walk with drift is statistically significant only for forecast horizons of 4-7 quarters ahead, and only at the $10 \%$ level (5\% for the 5-quarter ahead regression).

We conclude that theoretically well specified approximations of external imbalances exhibit a statistically significant and economically important relationship with subsequent Swiss franc returns, supporting the findings of GR for US data.

\section{Robustness}

\subsection{Time variation in the parameters}

There is no reason why we should expect the coefficients in regression (35) to be stable. First, $\beta_{1}$ could change over time as the discount rate $\hat{\rho}_{t+j}$ in the approximation of the intertemporal budget constraint varies, reflecting changing trends in ex-post growth-adjusted returns $\bar{R}_{t} / \bar{\Gamma}_{t}$ and trends in assets, liabilities, exports and imports. Second, $\beta_{1}$ could change because the

\footnotetext{
${ }^{14}$ As Clark and West (2006) show, under the null of no predictability, $\beta_{1}=0$ in regression (35), the $M P S E$ of the unrestricted model, $M S P E_{n x a}$, is expected to be larger than that of the random walk. This is the case because in the unrestricted model parameters are estimated which under the null have no predictive power.
} 
currency decomposition of assets and liabilities varies over time. This would imply that a given change in exchange rates has a varying impact on portfolio returns $\hat{r}_{t}$. Finally, the elasticity of net exports with respect to the exchange rate could also change over time.

To test whether the relationship between external imbalances and subsequent exchange rate returns is stable over time we employ the quasi-local-level test developed by Elliott and Müller (2006). They show that this test is asymptotically equivalent to the optimal tests for a wide range of processes for time variation. Therefore, we do not need to make specific assumptions about the particular process governing the time variation of coefficients. The null hypothesis of parameter stability is rejected if the test statistic is smaller (more negative) than the critical values, which are tabulated in Elliott and Müller (2006). This test has so far been applied in only few applied papers, including Goldberg and Klein (2011) and Grisse and Nitschka (2013).

Table 4 reports test statistics for the null hypothesis that $\beta_{0}$ and $\beta_{1}$ in regressions (35) are jointly stable, as well as for the null that $\beta_{0}$ is stable (computed under the assumption that $\beta_{0}$ does not change over time). Perhaps surprisingly, we find no evidence for time variation in the link between Swiss external imbalances versus the rest of the world and effective exchange rate returns: for the regressions with $n x a^{*}$ as dependent variable (computed again with the baseline value of $\left.\tau_{t}=\max \left(n x_{t}\right)+0.05\right)$, the null of parameter stability can typically not be rejected at conventional levels of statistical significance. One conclusion is that movements in trade weights employed in the effective exchange rate index are a good approximation for movements in portfolio weights across currencies.

\subsection{Alternative approximations}

Section 3 used approximation $n x a^{*}$ in (31) with a constant adjustment factor $\tau_{t}=\max \left(n x_{t}\right)+\tau$ to predict exchange rate movements. The constant $\tau>0$ was chosen as small as possible to minimize approximation error, while at the same time large enough to reasonably guarantee $n i_{t}^{*}>0$ out-of-sample. In this section we explore the properties of $n x a^{*}$ for various choices of $\tau_{t}$, and discuss the robustness of our results for these alternative approximations. We focus on $\tau_{t}=\max \left(n x_{t}\right)+\tau$ with $\tau$ ranging from 0.01 (as small as possible for the approximation to remain valid in-sample) to 0.4 , which would allow net exports as percent of (quarterly) GDP to rise 40 percent of (quarterly) GDP above their largest in-sample value (i.e., to about 50 percent of GDP). We also explore an alternative choice of $\tau_{t}=\theta n f a_{t}$ for a range of possible values for the constant $\theta>0$, beginning with $\theta=0.03$ which is just large enough to ensure the approximation is valid.

Figure 7 shows paths of $n x a^{*}$, approximating trend deviations in Swiss external imbalances versus the rest of the world. The alternative measures (normalized to have zero mean and a standard deviation of one) move together closely. For small values of $\tau_{t}$ the approximation $n x a^{*}$ shows stronger movements, as small absolute deviations from trends close to zero translate into large log deviations from trends. Figure 8 reports the corresponding approximation errors to the linearized accumulation identity (30), computed with a constant discount rate. For both specifications the approximation errors are very persistent, but less volatile than those from the 
GR measure. The approximation based on $\theta$ is less volatile again than that based on $\tau$. Table 5 reports results for coefficient $\beta_{1}$ in our baseline regression (35) for Swiss franc effective returns. The results for alternative values of $\tau$ are robust, with $\beta_{1}$ positive and strongly statistically significant across specifications and forecast horizons. For the alternative approximation with $\tau_{t}=\theta n f a_{t}$ we also find the expected positive coefficient for short- and medium-term forecast horizons, but the relationship between this alternative measure and Swiss franc returns is weak except for small values of $\theta$.

\section{Conclusion}

Appropriately defined measures of trend deviations in net exports and net foreign assets provide useful information about subsequent exchange rate movements, as expected based on the intertemporal budget constraint. This paper provides evidence supporting this claim, first advanced by Gourinchas and Rey (2007), for Switzerland.

We propose a simple twist to the Gourinchas and Rey (2007) approximation for the accumulation identity of the external portfolio that is valid for countries that have been consistently net creditors (or net debtors) throughout the sample. The advantages of the proposed approach are that it does not require the specification of trend shares for trend flows and portfolio positions, which can make the approximation more accurate, and that it can be applied to countries which are simultaneously net creditors and net exporters (or net debtors, net importers) over the sample period. We apply this approximation to trend deviations in Swiss net exports and net foreign assets and find that it is a useful signal for subsequent nominal effective Swiss franc returns. 


\section{References}

[1] Bernanke, B.S., T. Laubach, F.S. Mishkin and A.S. Posen (2001), Inflation targeting: lessons from the international experience, Princeton, NJ: Princeton University Press.

[2] Campbell, J.Y. and R.J. Shiller (1988), "The dividend-price ratio and expectations of future dividends and discount factors", Review of Financial Studies 1(3), 195-228.

[3] Campbell, J.Y. and N.G. Mankiw (1989), "Consumption, income, and interest rates: reinterpreting the time series evidence", NBER Macroeconomics Annual 1989, 185-216.

[4] Cardarelli, R. and P.T. Konstantinou (2007), "International financial adjustment: evidence from the G6 countries", unpublished working paper.

[5] Clark, T.E. and K.D. West (2006), "Using out-of-sample mean squared prediction errors to test the martingale difference hypothesis", Journal of Econometrics 135(1-2), 155-186.

[6] Corsetti, G. and P.T. Konstantinou (2012), "What drives US foreign borrowing? Evidence on the external adjustment to transitory and permanent shocks", American Economic Review 102(2), 1062-1092.

[7] Elliott, G. and U.K. Müller (2006), "Efficient tests for general persistent time variation in regression coefficients", Review of Economic Studies 73(4), 907-940.

[8] Evans, M.D.D. (2012), "International capital flows and debt dynamics", IMF Working Paper 12/175, July 2012.

[9] Goldberg, L.S. and M.W. Klein (2011), "Evolving perceptions of central bank credibility: the ECB experience", NBER International Seminar in Macroeconomics 2010, 153-182.

[10] Gourinchas, P.-O. and H. Rey (2005), "International Financial Adjustment", NBER Working Paper 11155, February 2005.

[11] Gourinchas, P.-O. and H. Rey (2007), "International Financial Adjustment", Journal of Political Economy 115(4), 665-703.

[12] Gourinchas, P.-O., H. Rey and K. Truempler (2012), "The financial crisis and the geography of wealth transfers", Journal of International Economics 88(2), 266-283.

[13] Grisse, C. and Nitschka, T. (2013), "On financial risk and the safe-haven characteristics of Swiss franc exchange rates", SNB working paper no. 2013-4.

[14] IMF (2012), "Switzerland: staff report for the 2012 article IV consultation", available at http://www . imf . org/external/pubs/cat/longres . aspx?sk=25895 . 0.

[15] Jordan, T. (2013), "Reconciling Switzerland's minimum exchange rate and the current account surplus", speech given at the Peterson Institute of International Economics, available at http://www.snb.ch/en/mmr/speeches/id/ref_20131008_tjn. 
[16] Lane, P.R. and G.M. Milesi-Ferretti (2001), "The external wealth of nations: measures of foreign assets and liabilities for industrial and developing countries", Journal of International Economics 55(2), 263-294.

[17] Lane, P.R. and G.M. Milesi-Ferretti (2007), "The external wealth of nations mark II: revised and extended estimates of foreign assets and liabilities, 1970-2007", Journal of International Economics 73(2), 223-250.

[18] Lane, P.R. and J.C. Shambaugh (2007), "Financial exchange rates and international currency exposures", American Economic Review 100(1), 518-540.

[19] Lettau, M. and S. Ludvigson (2001), "Consumption, aggregate wealth, and expected stock returns", Journal of Finance 56(3), 815-849.

[20] Meese, R.A. and K. Rogoff (1983), "Empirical exchange rate models of the seventies: do they fit out of sample?" Journal of International Economics 14(1-2), 3-24.

[21] Rich, Georg (2003), "Swiss monetary targeting 1974-1996: the role of internal policy analysis", ECB working paper no. 236, June 2003.

[22] SNB (2007), The Swiss National Bank 1907-2007, Zürich: Verlag Neue Zürcher Zeitung. Also available at http://www.snb.ch/en/iabout/snb/id/snb_100\#t5.

[23] Stoffels, N. and C. Tille (2007), "Why are Switzerland's foreign assets so low? The growing financial exposure of a small open economy", Staff Report no. 283, April 2007.

[24] Whelan, K. (2008), "Consumption and expected asset returns without assumptions about unobservables", Journal of Monetary Economics 55(7), 1209-1221. 


\section{Appendix: data sources}

Foreign assets and liabilities: annual data is from Lane and Milesi-Ferreti (2007). ${ }^{15}$ We use linear interpolation to obtain quarterly data. For Switzerland we combine this with data on external positions from the SNB (quarterly from 1999, annual from 1983), available at http: //www.snb.ch/en/iabout/stat/statpub/iip/stats/iip.

Exports and imports of goods and services: quarterly seasonally adjusted data in current prices is obtained from the IMF IFS database, via Datastream.

Wealth: quarterly data on seasonally adjusted nominal GDP is obtained from the IMF IFS database, via Datastream. For Switzerland we alternatively use data on household wealth compiled by the SNB, available at http://www.snb.ch/en/iabout/stat/statpub/vph/stats/ wph.

Nominal effective exchange rates: quarterly data on trade-weighted exchange rates are obtained from the IMF IFS database, via Datastream.

\section{Tables and figures}

Table 1: Parameters in the GR approximation for selected countries

\begin{tabular}{lrrrc} 
& $\mu^{a}$ & $\mu^{x}$ & $\rho$ & sample \\
\hline Australia & -18.63 & -0.94 & 1.01 & $1970 \mathrm{Q} 4-2012 \mathrm{Q} 4$ \\
Euro Area & -9.40 & 21.34 & 0.96 & $1995 \mathrm{Q} 1-2012 \mathrm{Q} 4$ \\
Italy & -4.88 & 52.96 & 0.99 & $1970 \mathrm{Q} 4-2012 \mathrm{Q} 4$ \\
Japan & 2.83 & 8.77 & 1.02 & $1970 \mathrm{Q} 4-2012 \mathrm{Q} 4$ \\
Spain & -1.96 & -12.00 & 1.02 & $1970 \mathrm{Q} 4-2012 \mathrm{Q} 4$ \\
Switzerland & 3.27 & 10.75 & 1.01 & $1970 \mathrm{Q} 4-2012 \mathrm{Q} 4$ \\
United States & -8.09 & -4.46 & 1.09 & $1970 \mathrm{Q} 4-2012 \mathrm{Q} 4$ \\
\hline \hline
\end{tabular}

Notes: This table reports parameters in the Gourinchas and Rey (2007) approximation for selected countries. $\mu^{a}$ is the trend share of external assets from equation (16). $\mu^{x}$ is the trend share of exports from equation (17). $\rho$ is the discount rate from equation (18). Following Gourinchas and Rey (2007) we estimate the trends by HP-filtering the log of the series, with a smoothing factor of $\lambda=2400000$.

\footnotetext{
${ }^{15}$ We thank Philip Lane for providing us with an updated version of this dataset.
} 
Table 2: Predictive regressions for nominal effective Swiss franc returns

\begin{tabular}{lccccccc} 
& \multicolumn{7}{c}{ Forecast horizon $k$ (quarters) } \\
& 1 & 2 & 3 & 4 & 8 & 12 & 16 \\
\hline \multirow{2}{*}{ (a) $n x a$} & & & & & & & \\
$\beta_{0}$ & & & & & & & \\
& $0.56^{* * *}$ & $0.57^{* * *}$ & $0.56^{* * *}$ & $0.57^{* * *}$ & $0.47^{* * *}$ & $0.38^{* *}$ & $0.29^{* *}$ \\
$\beta_{1}$ & $(0.19)$ & $(0.18)$ & $(0.17)$ & $(0.16)$ & $(0.16)$ & $(0.15)$ & $(0.11)$ \\
& $0.45^{*}$ & $0.51^{* *}$ & $0.52^{* *}$ & $0.54^{* *}$ & 0.25 & 0.07 & -0.07 \\
$\bar{R}^{2}$ & $(0.23)$ & $(0.23)$ & $(0.21)$ & $(0.21)$ & $(0.20)$ & $(0.18)$ & $(0.10)$ \\
Observations & 0.03 & 0.05 & 0.08 & 0.11 & 0.05 & 0.01 & 0.01 \\
\hline
\end{tabular}

(b) $n x a^{*}$

\begin{tabular}{lccccccc}
$\beta_{0}$ & $0.59^{* * *}$ & $0.61^{* * *}$ & $0.61^{* * *}$ & $0.62^{* * *}$ & $0.55^{* * *}$ & $0.47^{* * *}$ & $0.36^{* * *}$ \\
& $(0.19)$ & $(0.18)$ & $(0.16)$ & $(0.15)$ & $(0.14)$ & $(0.13)$ & $(0.12)$ \\
$\beta_{1}$ & $0.51^{* * *}$ & $0.58^{* * *}$ & $0.60^{* * *}$ & $0.64^{* * *}$ & $0.42^{* * *}$ & $0.26^{*}$ & 0.09 \\
& $(0.17)$ & $(0.17)$ & $(0.15)$ & $(0.14)$ & $(0.12)$ & $(0.14)$ & $(0.16)$ \\
$\bar{R}^{2}$ & 0.05 & 0.10 & 0.15 & 0.21 & 0.16 & 0.10 & 0.02 \\
Observations & 125 & 124 & 123 & 122 & 118 & 114 & 110 \\
\hline \hline
\end{tabular}

Notes: This table reports results from regressions $\Delta e_{t+k}=\beta_{0}+\beta_{1} X_{t}+\varepsilon_{t}$, where $\Delta e_{t+k}=\ln \left(E_{t+k} / E_{t}\right) / k$ is the per-quarter log return of the Swiss franc nominal effective (trade-weighted) exchange rate and $X_{t} \in$ $\left\{n x a, n x a^{*}\right\} . \quad n x a$ is the Gourinchas-Rey (2007) approximation. $n x a^{*}$ is the approximation proposed in (31) with $\tau_{t}=\max \left(n x_{t}\right)+0.05$. A positive coefficient $\beta_{1}>0$ implies that above-trend Swiss external imbalances are associated with an appreciation of the Swiss franc. ***,** and * denote significance at the 1\%, $5 \%$ and $10 \%$ level, respectively. Newey-West standard errors with $k-1$ lags in parentheses. The regressions use quarterly data from 1980 Q1 to 2011 Q2. 
Table 3: Tests for out-of-sample predictability of nominal effective Swiss franc returns

\begin{tabular}{llllcccc} 
& \multicolumn{9}{c}{ Forecast horizon $k$ (quarters) } \\
& 1 & 2 & 3 & 4 & 8 & 12 & 16 \\
\hline
\end{tabular}

(a) $n x a$

$M S P E_{n x a} / M S P E_{r w}$

$\triangle M S P E_{r w}$-adjusted

$\begin{array}{cc}0.87 & 0.76 \\ 0.58^{* * *} & 0.69^{* * *}\end{array}$

0.73

0.66

0.69

$\begin{array}{ll}0.68 & 0.71\end{array}$

$\triangle M P E_{n a} / M S P E_{r u d}$

$(3.19)$

$(3.31)$

$(2.53)$

$0.73^{* *}$

$0.40 * *$

$0.26^{* *} \quad 0.16^{* * *}$

$M S P E_{n x a} / M S P E_{\text {rwd }}$

1.03

0.99

1.01

(2.31)

(2.09)

(1.75)

$\triangle M S P E_{r w d}$-adjusted

0.10

0.20

0.17

0.93

1.09

1.07

1.13

$(0.47)$

(1.09)

(0.92)

$0.25^{*}$

0.06

0.02

$-0.01$

$T_{\text {out }}$

46

45

(1.43)

(0.40)

(0.23) $\quad(-0.11)$

$T_{\text {in }}$

79

78

77

43

39

35

31

72

68

64

(b) $n x a_{\tau}^{*}, \tau=0.05$

\begin{tabular}{lccccccc}
$M S P E_{n x a} / M S P E_{r w}$ & 0.86 & 0.76 & 0.74 & 0.69 & 0.76 & 0.57 & 0.72 \\
$\Delta M S P E_{r w^{-}}$-adjusted & $0.88^{* * *}$ & $1.13^{* * *}$ & $1.14^{* * *}$ & $1.45^{* * *}$ & $0.85^{* *}$ & $0.44^{*}$ & $0.16^{* *}$ \\
& $(2.89)$ & $(3.17)$ & $(2.58)$ & $(2.51)$ & $(2.09)$ & $(1.64)$ & $(2.31)$ \\
$M S P E_{n x a} / M S P E_{r w d}$ & 1.02 & 0.98 & 1.02 & 0.97 & 1.20 & 0.89 & 1.16 \\
$\Delta M S P E_{r w d}$-adjusted & 0.12 & $0.24^{* *}$ & $0.22^{*}$ & $0.40^{* *}$ & 0.14 & $0.08^{* *}$ & -0.02 \\
& $(0.59)$ & $(1.68)$ & $(1.41)$ & $(1.73)$ & $(1.11)$ & $(1.69)$ & $(-0.27)$ \\
$T_{\text {out }}$ & 46 & 45 & 44 & 43 & 39 & 35 & 31 \\
$T_{\text {in }}$ & 79 & 78 & 77 & 76 & 72 & 68 & 64 \\
\hline \hline
\end{tabular}

Notes: This table reports tests of out-of-sample predictive power, comparing regression model (35) against a random walk $(r w)$ and a random walk with drift $(r w d) . M S P E_{r w} / M S P E_{n x a}$ and $M S P E_{r w d} / M S P E_{n x a}$ denote the ratios of out-of-sample mean-square-errors of the null model versus regression model (35). $\Delta \mathrm{MSPE}$-adjusted is the Clark-West (2006) adjusted difference of mean square errors. $t$-statistics in parentheses. $* * *, * *$ and $*$ indicate that the null that a random walk with/without drift outperforms model (35) is rejected at the $1 \%, 5 \%$ and $10 \%$ level, respectively (one-sided test). $T_{\text {out }}$ is the length of the out-of-sample period, $T_{i n}$ is the length of the in-sample period. The initial in-sample begins in 1980 Q1 and ends in 1999 Q4, the end of the out-of-sample predictions is $2011 \mathrm{Q} 2$. 
Table 4: Tests for gradual time variation

\begin{tabular}{lccccccc} 
& \multicolumn{8}{c}{ Forecast horizon $k$ (quarters) } \\
& 1 & 2 & 3 & 4 & 8 & 12 & 16 \\
\hline$H_{0}: \beta_{1}$ stable & -4.65 & -3.51 & -3.50 & -3.98 & $-7.49^{*}$ & -6.93 & -4.76 \\
$H_{0}: \beta_{0}, \beta_{1}$ stable & -9.76 & -8.84 & -9.32 & -10.30 & -12.05 & -11.60 & -10.40 \\
\hline \hline
\end{tabular}

Notes: This table reports test statistics of the quasi-local-level test proposed by Elliott and Müller (2006) for the regressions in Table 2, with $n x a^{*}$ as dependent variable (computed with $\left.\tau_{t}=\max \left(n x_{t}\right)+0.05\right)$. The null hypothesis is rejected if the test statistics are sufficiently negative. The test statistics for the null that $\beta_{1}$ is stable is computed under the assumption that $\beta_{0}$ is stable as well. The critical values with one (two) time-varying parameter(s) are $-11.05,-8.36$ and -7.14 $(-17.57,-14.32$ and -12.80$)$ for the $1 \%, 5 \%$ and $10 \%$ level, respectively. ${ }^{* * *},{ }^{* *}$ and $*$ denote rejection of the null at the $1 \%, 5 \%$ and $10 \%$ level. 
Table 5: Predictive regressions for nominal effective Swiss franc returns: robustness to alternative approximations

\begin{tabular}{|c|c|c|c|c|c|c|c|}
\hline & \multicolumn{7}{|c|}{ Forecast horizon $k$ (quarters) } \\
\hline & 1 & 2 & 3 & 4 & 8 & 12 & 16 \\
\hline \multirow{2}{*}{\multicolumn{8}{|c|}{ (a) $n x a^{*}$ with $\tau_{t}=\max \left(n x_{t}\right)+\tau$}} \\
\hline & & & & & & & \\
\hline$\beta_{1}$ & $0.51^{* * *}$ & $0.56^{* * *}$ & $0.58^{* * *}$ & $0.61^{* * *}$ & $0.52^{* * *}$ & $0.41^{* * *}$ & 0.22 \\
\hline $\bar{R}^{2}$ & 0.06 & 0.11 & 0.16 & 0.22 & 0.21 & 0.19 & 0.05 \\
\hline \multicolumn{8}{|l|}{$\tau=0.1$} \\
\hline$\beta_{1}$ & $0.45^{* *}$ & $0.52^{* * *}$ & $0.55^{* * *}$ & $0.59^{* * *}$ & $0.34^{* *}$ & 0.18 & 0.05 \\
\hline $\bar{R}^{2}$ & 0.04 & 0.08 & 0.12 & 0.18 & 0.11 & 0.06 & 0.01 \\
\hline \multicolumn{8}{|l|}{$\tau=0.2$} \\
\hline$\beta_{1}$ & $0.35^{*}$ & $0.43^{* *}$ & $0.46^{* * *}$ & $0.50^{* * *}$ & $0.25^{*}$ & 0.13 & 0.03 \\
\hline $\bar{R}^{2}$ & 0.02 & 0.05 & 0.09 & 0.14 & 0.07 & 0.04 & 0.00 \\
\hline \multicolumn{8}{|l|}{$\tau=0.3$} \\
\hline & $0.30^{*}$ & $0.37^{* *}$ & $0.41^{* *}$ & $0.45^{* * *}$ & $0.21^{*}$ & 0.10 & 0.03 \\
\hline $\bar{R}^{2}$ & 0.02 & 0.04 & 0.08 & 0.12 & 0.06 & 0.03 & 0.00 \\
\hline \multicolumn{8}{|l|}{$\tau=0.4$} \\
\hline$\beta_{1}$ & 0.27 & $0.34^{* *}$ & $0.38^{* *}$ & $0.42^{* *}$ & 0.19 & 0.09 & 0.03 \\
\hline $\bar{R}^{2}$ & 0.01 & 0.04 & 0.07 & 0.10 & 0.05 & 0.02 & 0.00 \\
\hline \multicolumn{8}{|c|}{ (b) $n x a^{*}$ with $\tau_{t}=\theta \times n f a_{t}$} \\
\hline$\theta=0.03$ & & & & & & & \\
\hline & $0.38^{* *}$ & $0.42^{* *}$ & $0.41^{* *}$ & $0.41^{* *}$ & 0.22 & 0.09 & -0.08 \\
\hline $\bar{R}^{2}$ & 0.02 & 0.04 & 0.06 & 0.08 & 0.05 & 0.01 & 0.02 \\
\hline \multicolumn{8}{|l|}{$\theta=0.04$} \\
\hline$\beta_{1}$ & 0.35 & $0.38^{*}$ & $0.37^{* *}$ & $0.37^{*}$ & 0.17 & 0.03 & -0.10 \\
\hline $\bar{R}^{2}$ & 0.02 & 0.03 & 0.04 & 0.06 & 0.03 & 0.00 & 0.03 \\
\hline \multicolumn{8}{|l|}{$\theta=0.05$} \\
\hline & 0.32 & $0.36^{*}$ & $0.35^{*}$ & $0.35^{*}$ & 0.14 & 0.01 & -0.11 \\
\hline $\bar{R}^{2}$ & 0.01 & 0.03 & 0.04 & 0.05 & 0.02 & 0.00 & 0.03 \\
\hline \multicolumn{8}{|l|}{$\theta=0.06$} \\
\hline$\beta_{1}$ & 0.31 & 0.34 & $0.33^{*}$ & 0.33 & 0.12 & -0.01 & -0.12 \\
\hline $\bar{R}^{2}$ & 0.01 & 0.03 & 0.03 & 0.04 & 0.01 & 0.00 & 0.04 \\
\hline \multicolumn{8}{|l|}{$\theta=0.1$} \\
\hline$\beta_{1}$ & 0.28 & 0.32 & 0.30 & 0.30 & 0.08 & -0.03 & -0.13 \\
\hline $\bar{R}^{2}$ & 0.01 & 0.02 & 0.03 & 0.04 & 0.01 & 0.00 & 0.04 \\
\hline
\end{tabular}

Notes: This table reports results from regressions $\Delta e_{t+k}=\beta_{0}+\beta_{1} n x a_{t}^{*}+\varepsilon_{t}$, where $\Delta e_{t+k}=\ln \left(E_{t+k} / E_{t}\right) / k$ is the per-quarter log return of the Swiss franc nominal effective (export-weighted) exchange rate, for alternative specifications of $n x a^{*} .{ }^{* * *},{ }^{* *}$ and ${ }^{*}$ denote significance at the $1 \%, 5 \%$ and $10 \%$ level, respectively. Newey-West standard errors with $k-1$ lags in parentheses. A positive coefficient $\beta_{1}>0$ implies that above-trend Swiss external imbalances are associated with an appreciation of the Swiss franc. The regressions use quarterly data from 1980 Q1 to 2011 Q2. 

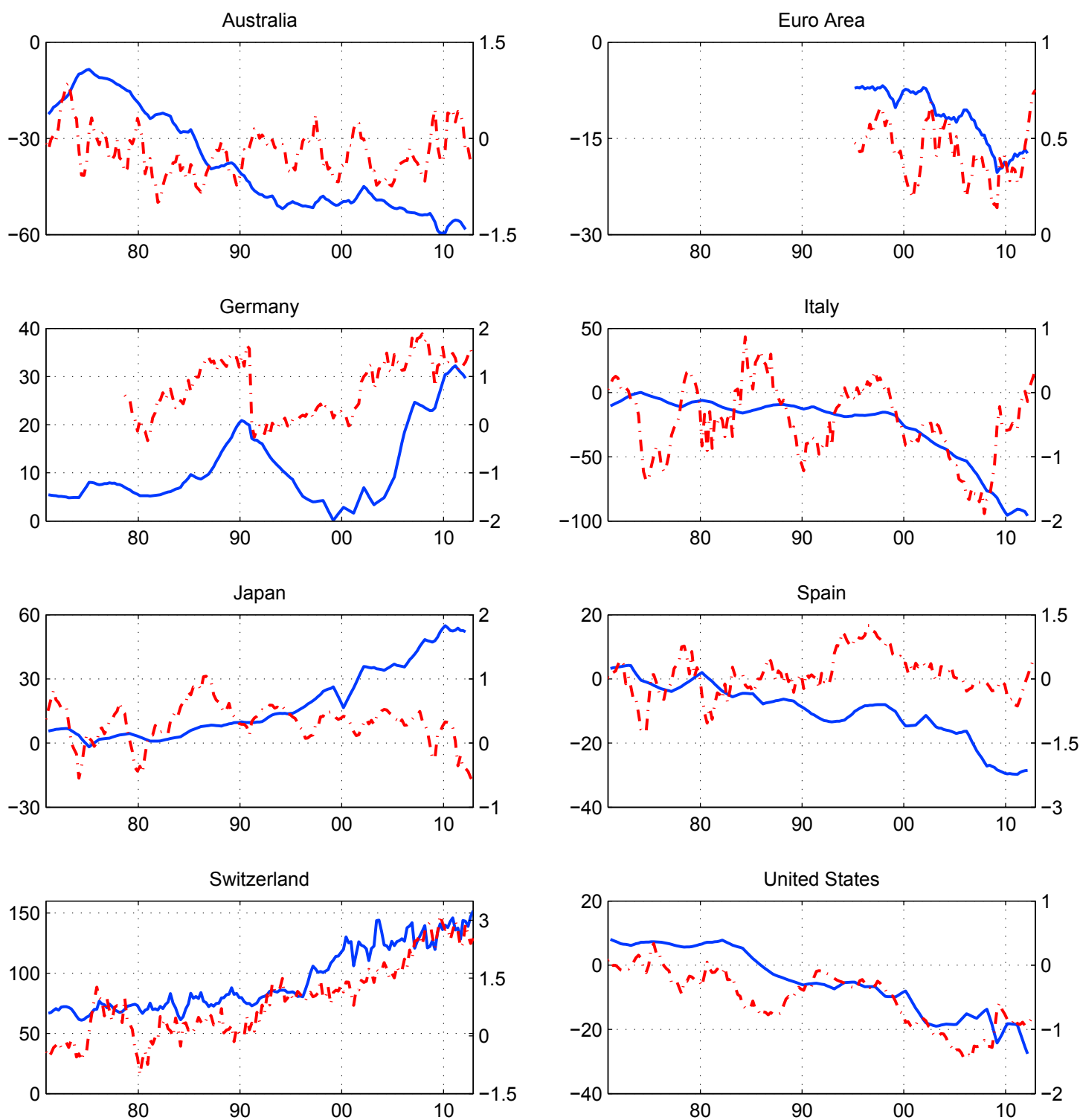

- net foreign assets (\% of GDP, Ihs)
- - net exports (\% of GDP, rhs)

Figure 1: External imbalances for selected countries. The blue solid line is net foreign assets (plotted against the left axis). The red broken line is net exports (plotted against the right axis). Data are percentages of annual GDP. Data for Germany before 1991 refer to the BRD. Sources: Lane and Milesi-Ferretti (2007), IMF IFS and SNB. 


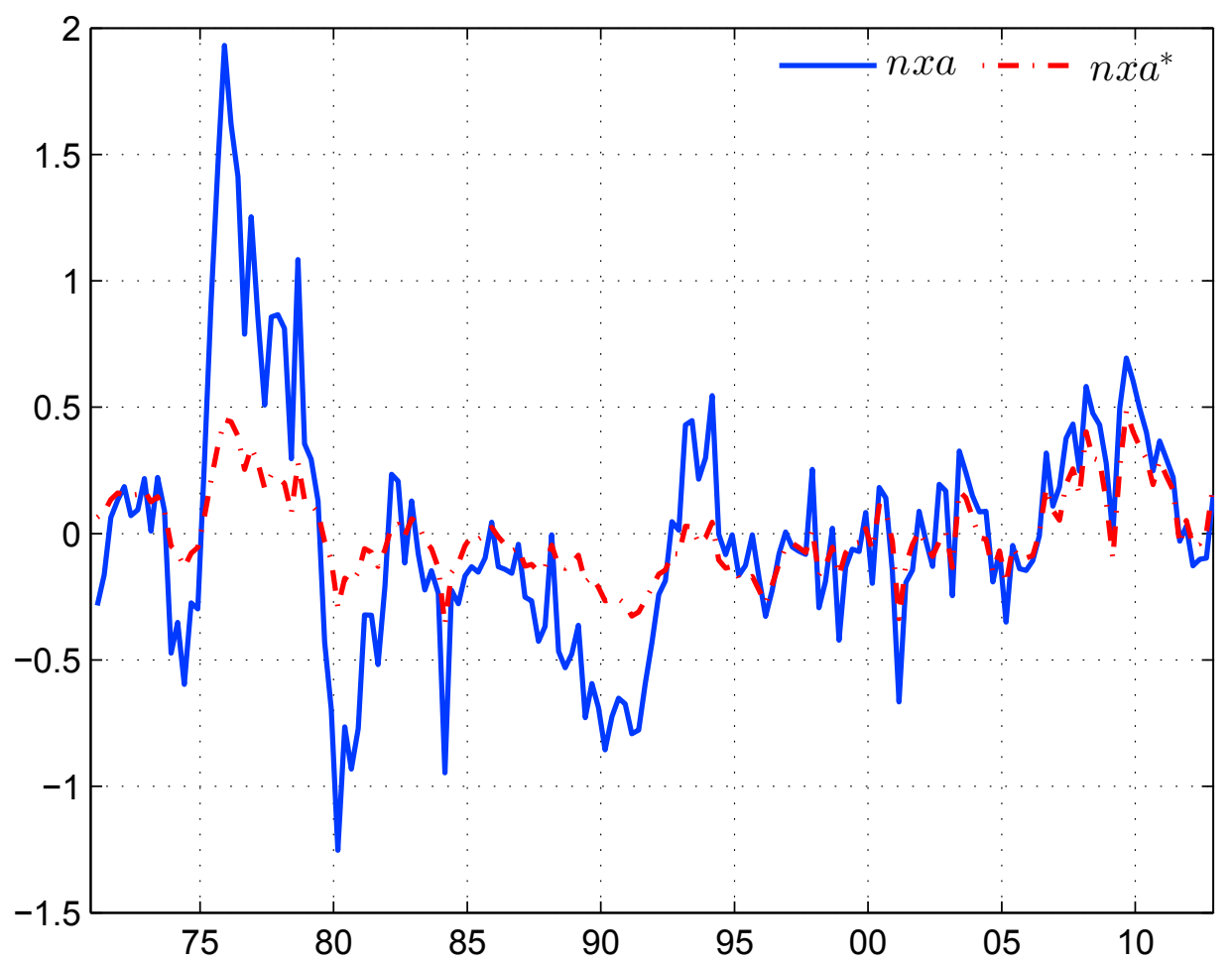

Figure 2: Alternative measures of Swiss external imbalances. $n x a$ is the Gourinchas-Rey (2007) approximation, equation (20). $n x a^{*}$ is the approximation proposed in (31) with $\tau_{t}=\max \left(n x_{t}\right)+$ 0.05 . 


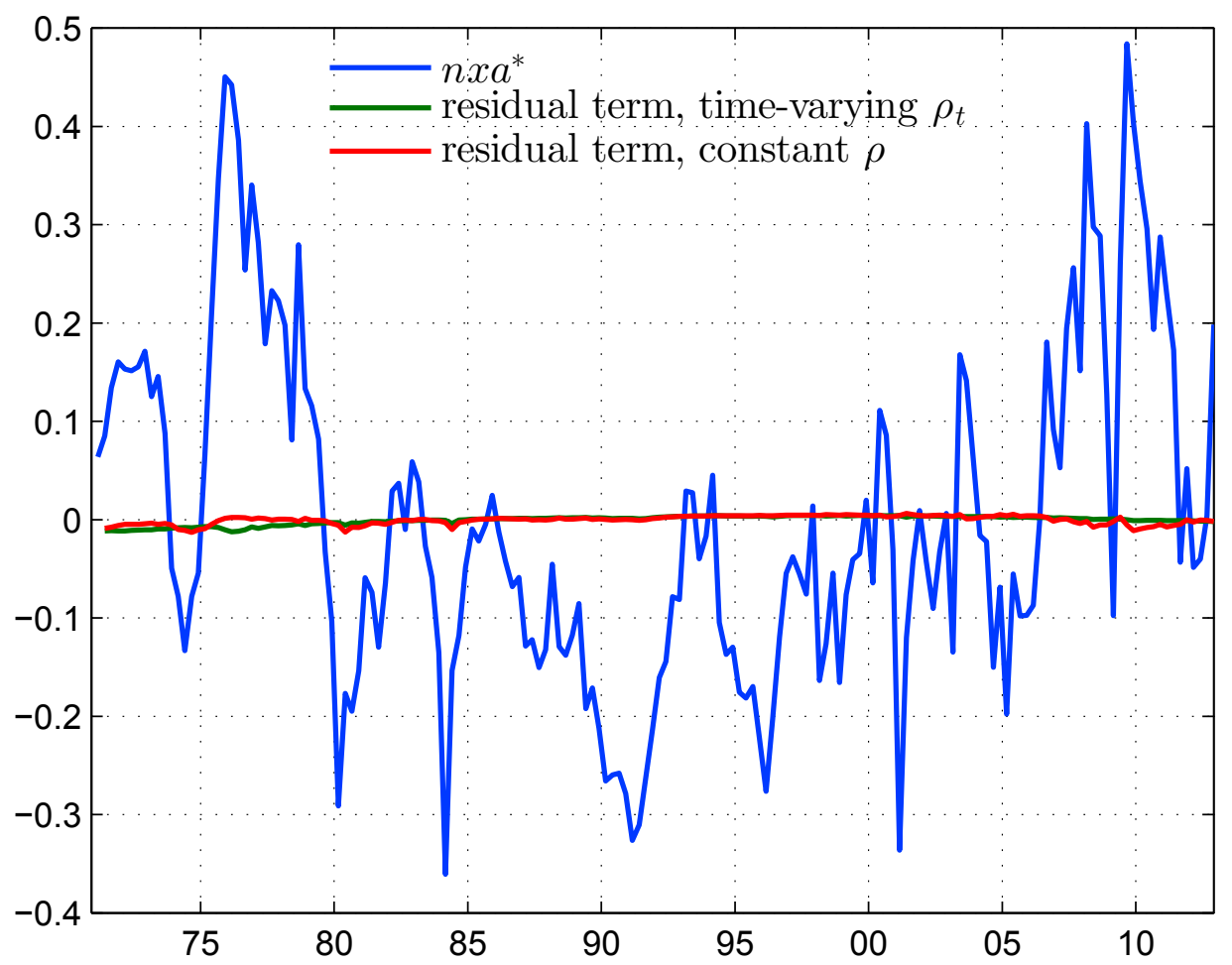

Figure 3: Accuracy of the $n x a^{*}$ approximation of the accumulation identity for Swiss net foreign assets. This figure compares the $n x a^{*}$ approximation of Swiss external imbalances, computed with $\tau_{t}=\max \left(n x_{t}\right)+0.05$, with two alternative measures of its approximation error. The approximation error is obtained as the residual term from equation (30), computed by subtracting the right-hand side of the equation from the left-hand side. 


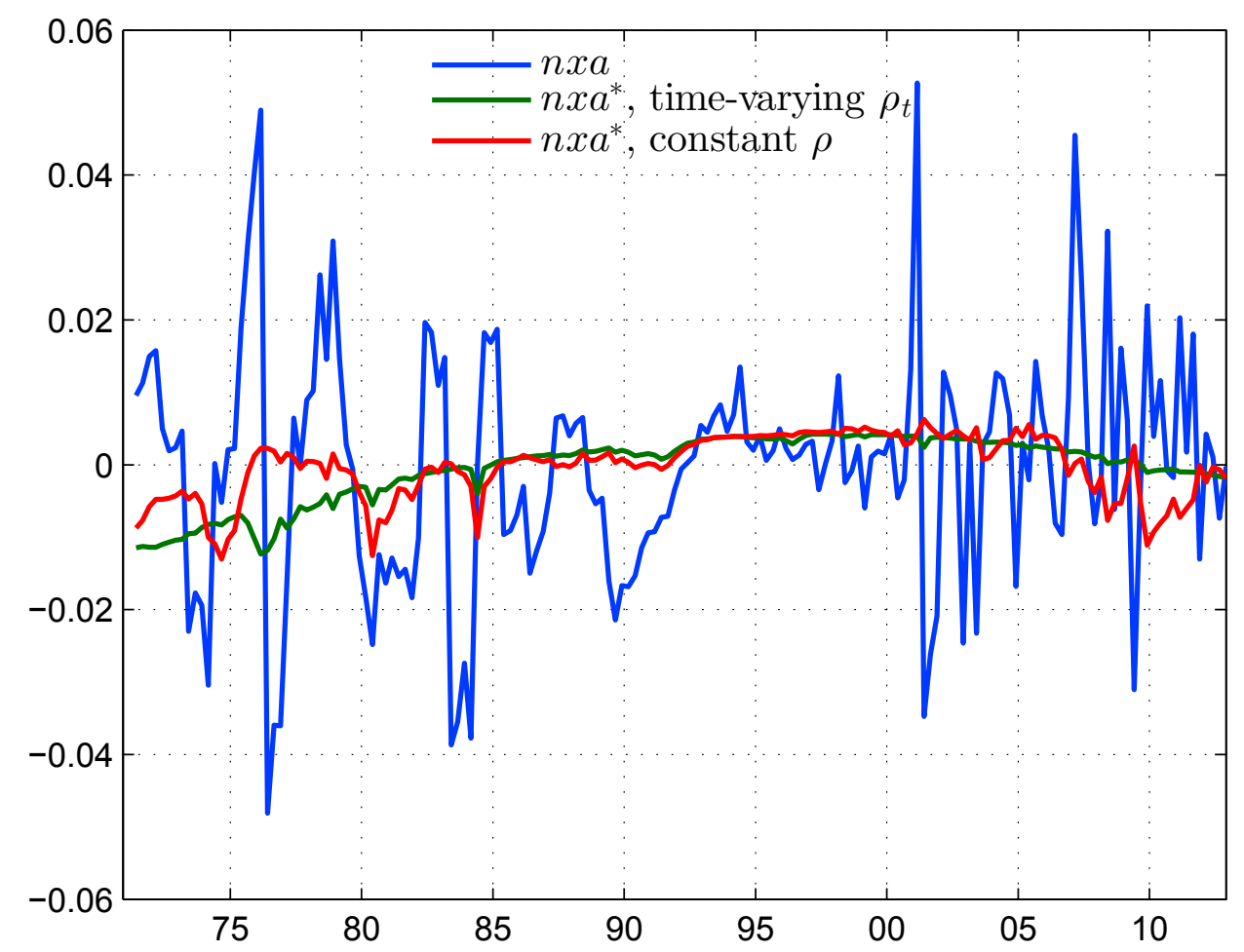

Figure 4: Accuracy of alternative approximations of the accumulation identity for Swiss net foreign assets. This Figure shows the error from equations (19) for the GR $n x a$ measure and (30) for $n x a^{*}$ with $\tau_{t}=\max \left(n x_{t}\right)+0.05$. The error is obtained by subtracting the right-hand side of the equation from the left-hand side. 


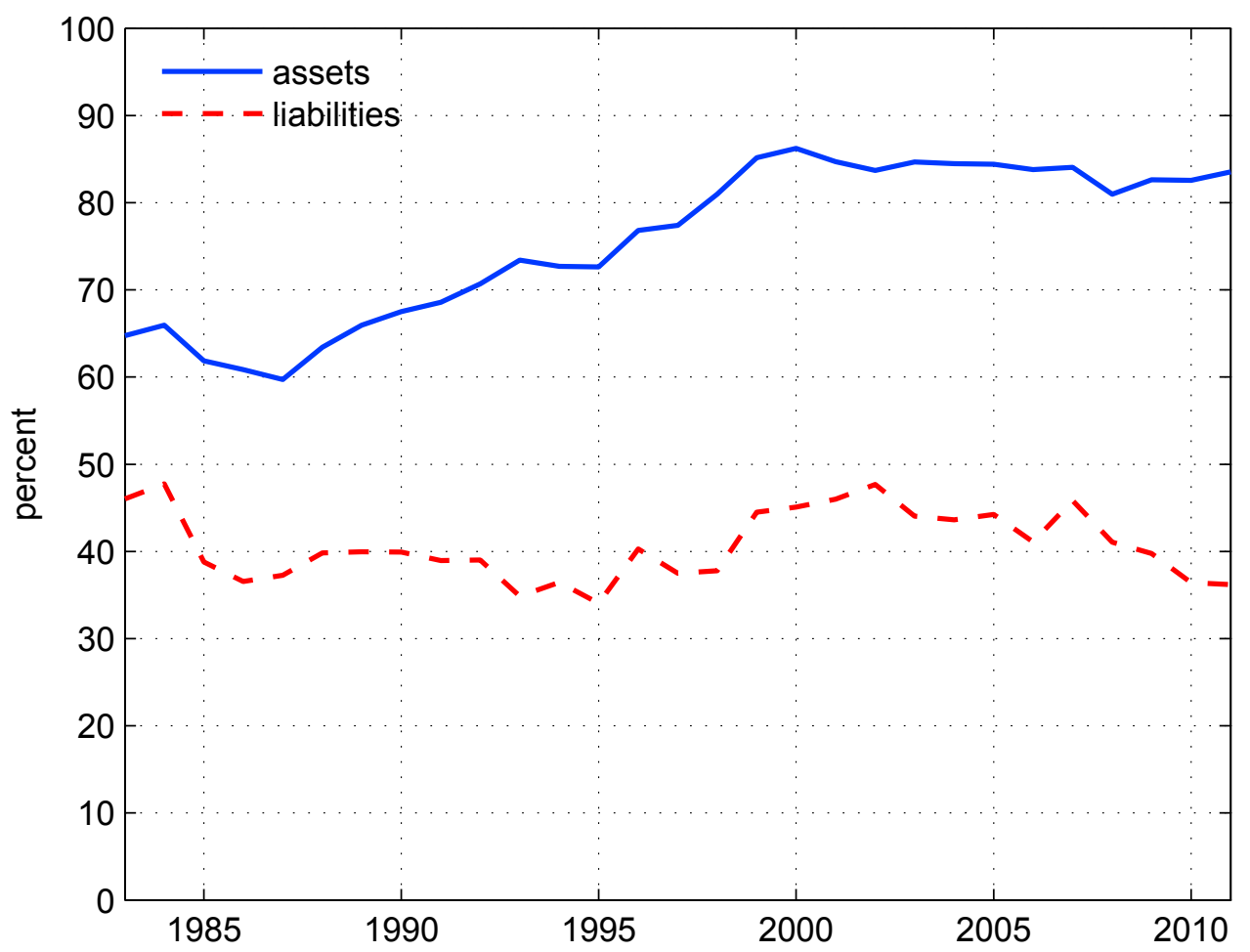

Figure 5: Share of Swiss external assets and liabilities denominated in foreign currency. Source: SNB. 

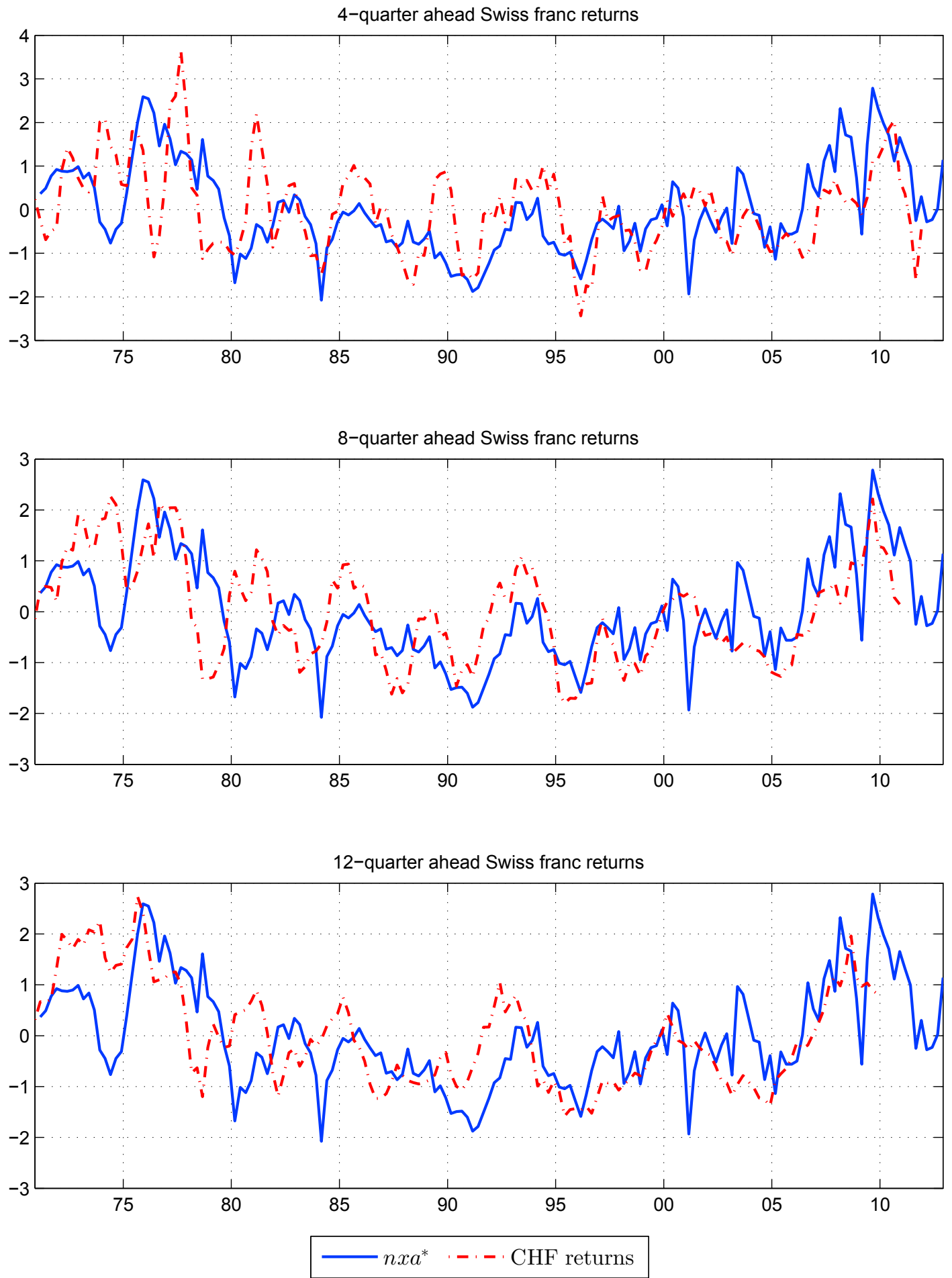

Figure 6: Comparison of Swiss cyclical external imbalances and Swiss franc returns. A positive exchange rate return corresponds to a Swiss franc appreciation. $n x a^{*}$ is the measure of cyclical Swiss external imbalances proposed in (31), computed with an adjustment factor of $\tau=\max \left(n x_{t}\right)+0.05$. All series are normalized to have a mean of zero and a standard deviation of one. For the forecast horizon $k$ we plot the return between $t$ and $t+k$ together with the value of $n x a^{*}$ in $t$. 
(a) $n x a^{*}, \tau_{t}=\max \left(n x_{t}\right)+\tau$

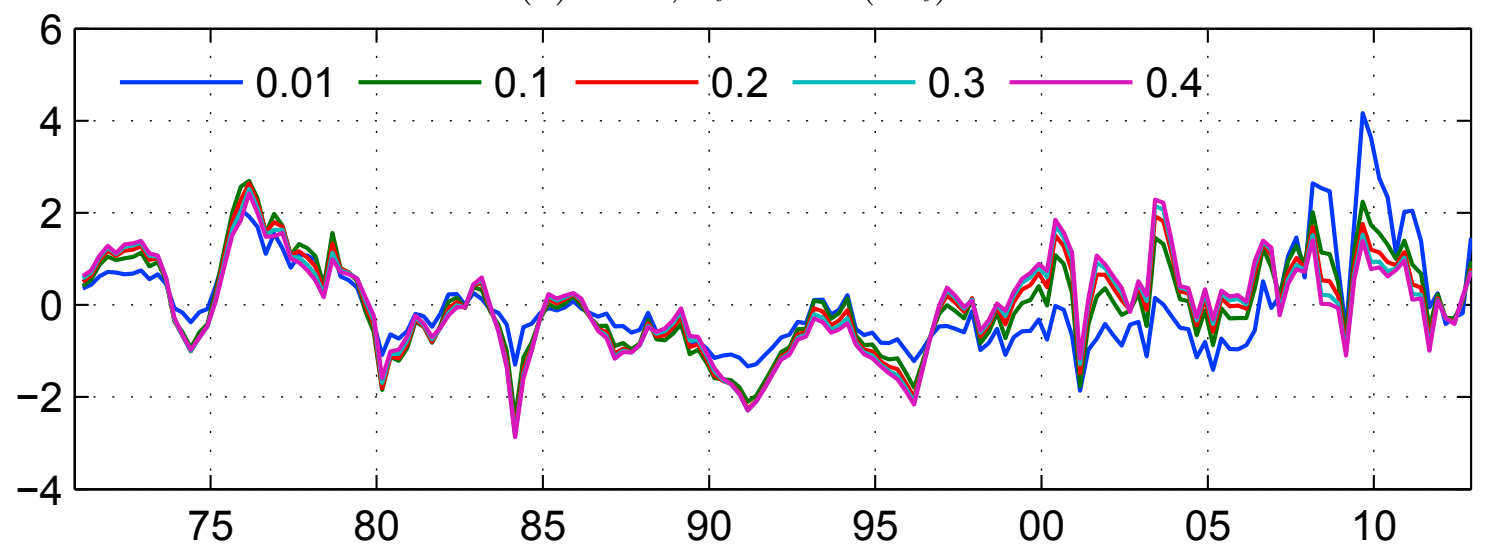

(b) $n x a^{*}, \tau_{t}=\theta \times n f a_{t}$

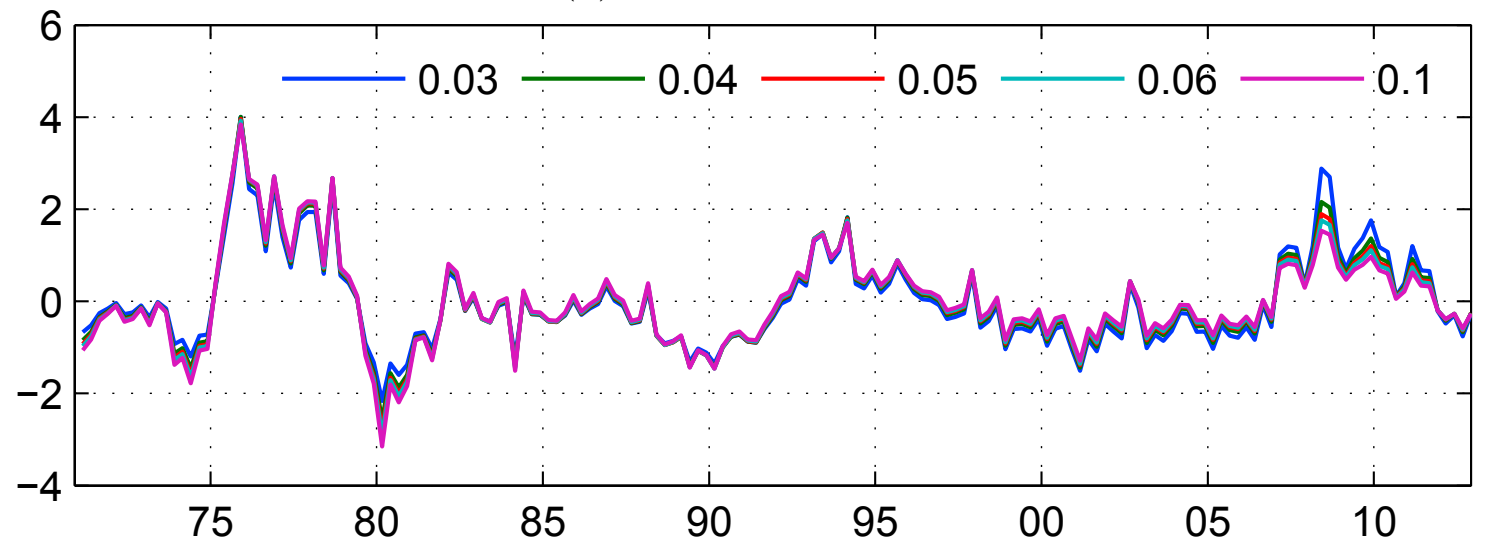

Figure 7: Alternative approximations to trend deviations in Swiss external imbalances, computed according to equation (31), for alternative specifications of $\tau_{t}$. Panel (a) shows $n x a^{*}$ with $\tau_{t}=\max \left(n x_{t}\right)+\tau$ for alternative values of $\tau$. Panel (b) shows $n x a^{*}$ with $\tau_{t}=\theta \times n f a_{t}$ for alternative values of $\theta$. All series are normalized to have a mean of zero and a standard deviation of one. 
(a) $n x a^{*}, \tau_{t}=\max \left(n x_{t}\right)+\tau$
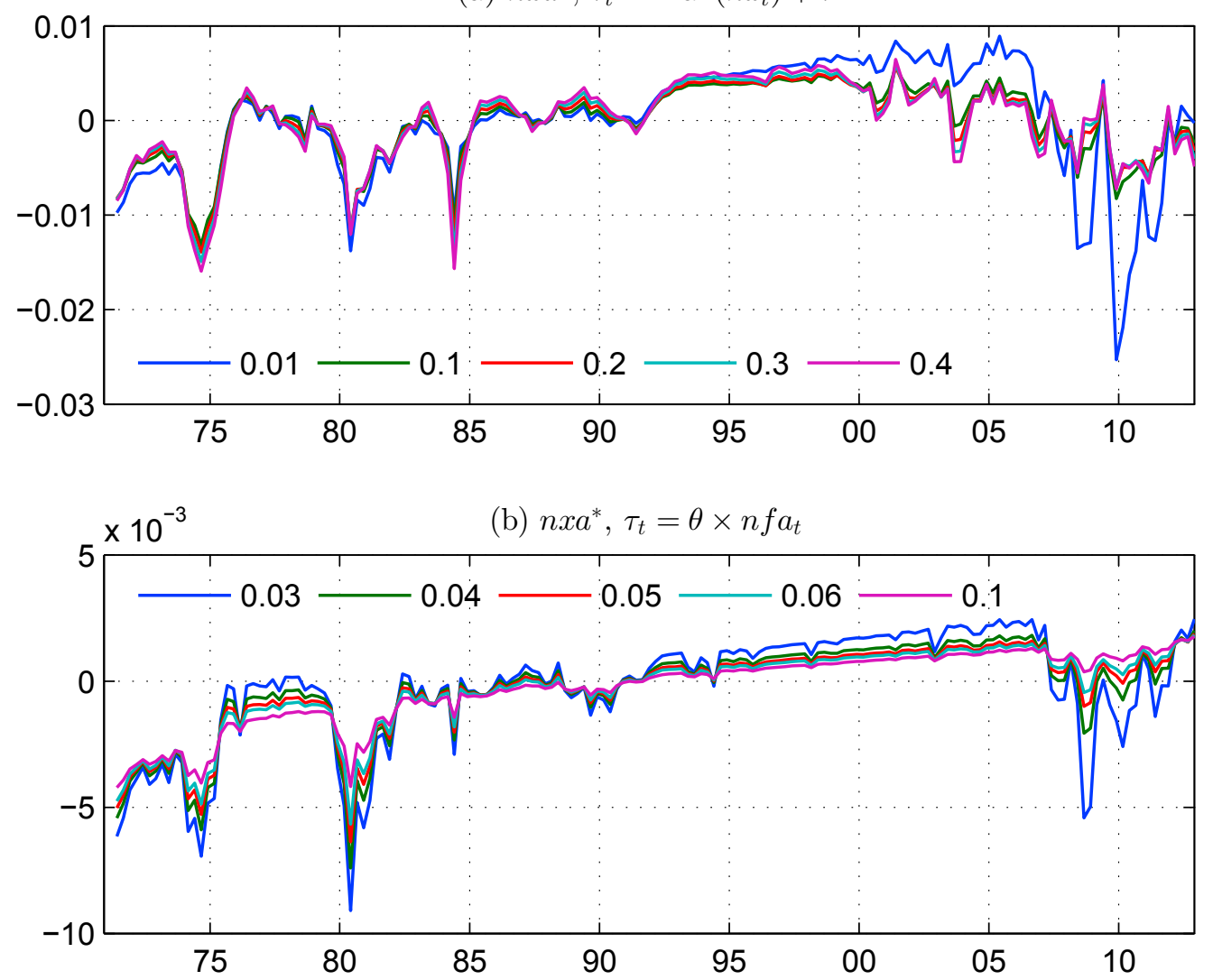

Figure 8: Approximation accuracy of $n x a^{*}$ for alternative specifications of $\tau_{t}$. Panel (a) shows the approximation error for $n x a^{*}$ with $\tau_{t}=\max \left(n x_{t}\right)+\tau$ for alternative values of $\tau$. Panel (b) shows the approximation error for $n x a^{*}$ with $\tau_{t}=\theta \times n f a_{t}$ for alternative values of $\theta$. 


\section{Recent SNB Working Papers}

2014-12 Christian Grisse and Thomas Nitschka: Exchange rate returns and external adjustment: evidence from Switzerland.

2014-11 Rina Rosenblatt-Wisch and Rolf Scheufele: Quantification and characteristics of household inflation expectations in Switzerland.

2014-10 Gregor Bäurle and Daniel Kaufmann: Exchange rate and price dynamics in a small open economy - the role of the zero lower bound and monetary policy regimes.

2014-9 Matthias Gubler and Christoph Sax: Skill-Biased Technological Change and the Real Exchange Rate.

2014-7 Konrad Adler and Christian Grisse: Real exchange rates and fundamentals: robustness across alternative model specifications.

2014-6 Matthias Gubler: Carry Trade Activities: A Multivariate Threshold Model Analysis.

2014-5 Raphael A. Auer and Aaron Mehrotra: Trade linkages and the globalisation of inflation in Asia and the Pacific.

2014-4 Cyril Monnet and Thomas Nellen: The Collateral Costs of Clearing.

2014-3 Filippo Brutti and Philip Sauré: Repatriation of Debt in the Euro Crisis: Evidence for the Secondary Market Theory.

2014-2 Simone Auer: Monetary Policy Shocks and Foreign Investment Income: Evidence from a large Bayesian VAR.
2014-1 Thomas Nitschka: The Good? The Bad? The Ugly? Which news drive (co)variation in Swiss and US bond and stock excess returns?

2013-11 Linda S. Goldberg and Christian Grisse: Time variation in asset price responses to macro announcements.

2013-10 Robert Oleschak and Thomas Nellen: Does SIC need a heart pacemaker?

2013-9 Gregor Bäurle and Elizabeth Steiner: How do individual sectors respond to macroeconomic shocks? A structural dynamic factor approach applied to Swiss data.

2013-8 Nikolay Markov and Thomas Nitschka: Estimating Taylor Rules for Switzerland: Evidence from 2000 to 2012.

2013-7 Victoria Galsband and Thomas Nitschka: Currency excess returns and global downside market risk.

2013-6 Elisabeth Beusch, Barbara Döbeli, Andreas Fischer and Pınar Yeşin: Merchanting and Current Account Balances.

2013-5 Matthias Gubler and Matthias S. Hertweck: Commodity Price Shocks and the Business Cycle: Structural Evidence for the U.S.

2013-4 Christian Grisse and Thomas Nitschka: On financial risk and the safe haven characteristics of Swiss franc exchange rates.

2013-3 Simone Meier: Financial Globalization and Monetary Transmission.
From 2014, this publication series will be renamed SNB Working Papers.

All SNB Working Papers are available for download at: www.snb.ch, Research

Subscriptions or individual issues can be ordered at: Swiss National Bank

Library

P.O. Box

$\mathrm{CH}-8022$ Zurich

Phone: +41446313284

Fax: +41446318114

E-mail: library@snb.ch 
